Old Dominion University

ODU Digital Commons

1978

The Reproductive Cycle of Microtus ochrogaster in Eastern

Kansas

Robert K. Rose

Michael S. Gaines

Follow this and additional works at: https://digitalcommons.odu.edu/biology_fac_pubs

Part of the Biology Commons, Population Biology Commons, and the Zoology Commons 


\title{
THE REPRODUCTIVE CYCLE OF MICROTUS OCHROGASTER IN EASTERN KANSAS ${ }^{1}$
}

\author{
ROBERT K. ROSE ${ }^{2}$ \\ AND \\ Michael S. Gaines \\ Department of Systematics and Ecology, University of Kansas, Lawrence 66045 USA
}

\begin{abstract}
About 800 Microtus ochrogaster were live-trapped at biweekly intervals from May 1971 through March 1973 in 3 grassland study areas in eastern Kansas, USA. Details of reproduction were determined by autopsy. Population density increased through the first winter, reached a peak in April 1972, then declined sharply during that summer and beyond.

Body length, but not body mass, tended to be positively related to density. Both sexes matured at about the same weight; development was somewhat prolonged during the winter months, especially in the winter preceding the population peak. Pregnancy rates were high, approaching maximal iteroparity, throughout the study, with intervals of nonbreeding in both Julys, and in August and December of the population decline. Embryo counts increased significantly during the months of peak density but did not diminish in the period of the population decline. There was no association between either maternal weight or parity and number of embryos. Corpora counts were not higher in heavy or multiparious $\$ \&$, nor did the level of prenatal mortality increase during the period of greatest density. Except for a few individuals taken in July and August 1971, o d with a mass $30 \mathrm{~g}$ or more were judged to be fertile, as were a majority of the 20 to $29-g \delta \delta$. Body weight and testes weight were significantly correlated in fertile $\delta \delta$ but not in nonfertile $\delta \delta$. These reproductive findings were applied to a model of population regulation of microtine cycles.

The pattern of reproduction of Kansas and Indiana prairie voles was compared. Three concordant lines of evidence seem to indicate that Kansas and possibly other geographical populations of prairie voles have adjusted the breeding schedule to accommodate both hot and dry summers and cold, snowy winters. Pregnancy rate, litter size, and adjusted testes weight all show a significant increase in MarchApril and September-October and a decrease in midsummer and midwinter. Thus the pattern of reproduction of Kansas prairie voles may represent a composite of the patterns shown by the dryadapted species, such as Microtus californicus, and the cold-adapted microtines, such as Microtus pennsylvanicus. Based on the observations of this study, Kansas prairie voles seem to have adjusted to both harsh seasons by breeding more or less continuously, with the midsummer depression possibly reflecting the Great Plains origin of the species, and the winter depression being a facultative response to weather, density, or quality of habitat.
\end{abstract}

Key words: Evolutionary strategy; Kansas; microtine rodent; Microtus ochrogaster; population cycle; population model; prairie vole; reproduction.

\section{INTRODUCTION}

Irruptions of microtine rodent populations are a part of the history and folklore of Eurasia and North America but have been the subject of systematic study only since about 1930. The dramatic changes in density, called "cycles," show periodicities of 2 to $5 \mathrm{yr}$ and amplitudes ranging from 1 or 2 to 600 individuals per 40.5 ares, depending on the species and locality. Weather, quantity and quality of food, predation, and the effects of disease and hormonal imbalance have been rejected as possible causes of cycles. The possibility that reproductive changes within a density cycle might be a driving force to produce oscillations was first examined by Hamilton (1941), who concluded that changes in density could be explained by changes

\footnotetext{
' Manuscript received 31 August 1976; accepted 23 June 1977.

${ }^{2}$ Present address: WAPORA, Inc, 6900 Wisconsin Avenue, N.W., Washington, D.C. 20015 USA.
}

in natality. Subsequent studies on a number of microtine species have failed to support Hamilton's observation that a reduction in litter size contributes substantially to the decline in numbers.

Lidicker (1973) has urged that populations of microtine rodents be examined in a community perspective, that is, with the view that several biotic and physical components are likely to be interacting to regulate the populations under study. We have tried to use this approach in our study of the prairie vole in eastem Kansas by monitoring dernographic events of a vole population on 4 live-trap grids (Gaines and Rose 1976), while documenting the details of reproductive and behavioral change in nearly 800 voles collected from May 1971 to March 1973 on off-grid sites nearby. This paper is specifically concerned with:

1) the change in levels of reproduction throughout the density cycle;

2) the possible role of reproduction in explaining density changes: and 
3) an examination of patterns of reproduction observed throughout the distribution of the species (including previous studies in eastern Kansas), with the hope that repeatable events will make prediction possible within a species, thereby giving a higher level of plausibility to generalizations made among species of microtine rodents (Krebs and Myers 1974).

\section{MATERIALS AND METHODS}

\section{Species composition}

We agree with Fitch (1957) that Microtus ochrogaster is the most numerous small mammal in eastern Kansas. However, densities of prairie deermice (Peromyscus maniculatus bairdii) and hispid cotton rats (Sigmodon hispidus) sometimes rivaled or even surpassed those of the prairie vole. Both species have annual density cycles (Cockrum 1948, Sadleir 1965) with greatest numbers in late autumn, and both share many food plants with the prairie vole (Menhusen 1963, Fleharty and Olson 1969). A third species, the southern bog lemming (Synaptomys cooperi), was also sympatric in all populations and on one occasion was more numerous than the prairie vole. Synaptomys is also a member of the subfamily Microtinae and is probably more like Microtus in its habits and requirements than any other local small mammal. Rarely caught mammals included Reithrodontomys megalotis, Reithrodontomys montanus (eastern and western harvest mice), Peromyscus leucopus (white-footed mouse), Zapus hudsonius (meadow jumping mouse), Mus musculus (house mouse), and the shrews Blarina brevicauda and Cryptotis parva.

\section{Study areas}

Three principal study areas were selected both to provide an estimate of the synchrony of density and reproduction in spatially isolated populations, and to obtain detailed reproductive information of individuals. Two were $14 \mathrm{~km}$ northeast of Lawrence and a third was $6.2 \mathrm{~km}$ west of the city. Four mark-recapture grids were trapped biweekly and provided information on density, survivorship and external reproductive features (Gaines and Rose 1976). These grids provided independent estimates of population density (by direct enumeration) and also reinforced information on changes in breeding and in age structure of the population. Voles were collected from 12 sampling sites for this study. Each study area contained 3 or more sampling sites in early successional stages, dominated by a perennial grass, cultivated brome (Bromus inermis). Common woody elements in such associations in eastern Kansas are red cedar (Juniperus virginiana) and honey locust (Gleditsia triacanthos).

Two study areas, Robinson Farm and the Nelson Research Tract, adjoin the University of Kansas Natural History Reservation; all are University owned and provided fields for the 4 demographic grids as well. Robinson Farm included sampling sites on a south-facing slope, sandy hilltop, and seasonally flooded lowland. The Nelson Tract, withdrawn from agricultural practice in the autumn of 1970 , also has rolling, terraced hills with variable soil and moisture gradients. The sampling sites there were placed in old hay meadows. The third study area, the Yankee Tank Creek watershed, included 3 sites on upland old field and 2 on native tall-grass prairie hayfields. Sampling site 12 , located in a lowland old field $4 \mathrm{~km}$ south of Lawrence, provided 1 sample of voles for autopsy and was not a part of the other 3 areas. A detailed description of the 3 study areas and 12 sampling sites, together with detailed weather information (see beyond), is available in Rose (1974).

Weather data were taken from the U.S. Weather Station in Lawrence and from a weather station maintained by Dr. and Mrs. Henry S. Fitch on the University of Kansas Natural History Reservation. Data from the latter location are limited to daily high and low temperatures and to rainfall or snowmelt. Annual and mean monthly temperatures at the Natural History Reservation are $\approx 2^{\circ} \mathrm{C}$ cooler than those recorded in the city.

Lawrence is situated near the western edge of the eastern hardwood forest at $38^{\circ} 58^{\prime}$ latitude and $95^{\circ} 16^{\prime}$ longitude with an elevation of $310 \mathrm{~m}$. The average annual temperature is $13.6^{\circ} \mathrm{C}$ and mean rainfall is 878 $\mathrm{mm}$. As is typical of continental climates, there is a great fluctuation in temperatures, especially during the cooler months. During the study, the number of frostfree days averaged 203, roughly from 10 April to 1 November. Only two thirds of the remaining days have temperatures $\angle 0^{\circ} \mathrm{C}$, and brief periods of moderate temperatures permit some growth of grasses during every month. Soils are rarely frozen for as long as 2 wk, and snow usually melts within a few days.

Rainfall varies greatly from month to month, with $70.0 \%$ of the precipitation falling during the $6 \mathrm{mo}$ from April through September. Much of the summer precipitation results from thunderstorm activity, and amounts received are locally variable. The wettest months, in decreasing order, are June, May, August, and July (range of 122 to $95 \mathrm{~mm}$ ) and the driest months are February, January, December, and November (range of 28 to $48 \mathrm{~mm}$ ). Both 1971 and 1972 were wetter than normal years as recorded in Lawrence ( 948 $\mathrm{mm}$ and $931 \mathrm{~mm}$, respectively), but 695 and $1,016 \mathrm{~mm}$ were recorded at the Natural History Reservation then. No protracted period of drought occurred during the study. Snowfall during the winter of 1970-1971 was $58.4 \mathrm{~cm} ; 53.4 \mathrm{~cm}$ fell the next winter, and a total of $50.8 \mathrm{~cm}$ was recorded during the winter of 1972 1973. Maximum depth of snow was $30.5 \mathrm{~cm}$, recorded in February 1971.

In summary, the weather was normal for most of the study, except somewhat wetter during the summer 
TABLE 1. Number of voles per 100 nights of live trapping. Values in italics represent the average $\overline{(X)}$ of 2 sites within an area for a given circuit. One circuit represents the amount of time required to return to a given site, $\approx 10$ wk in this study. Numbers in parentheses are estimates taken but invalid because of local disturbances. Site 12, not in any of the 3 main study areas, yielded one estimate $\left(^{*}\right)$ based on both live and snap traps. Dates are inclusive

\begin{tabular}{|c|c|c|c|c|c|c|c|c|c|}
\hline \multirow[b]{2}{*}{ Locality } & \multicolumn{9}{|c|}{ Circuits } \\
\hline & $\begin{array}{c}1 \\
27 \text { May- } \\
3 \text { Aug } \\
1971\end{array}$ & $\begin{array}{l}2 \\
8 \mathrm{Aug}- \\
2 \mathrm{Oct}\end{array}$ & $\begin{array}{l}3 \\
18 \text { Oct- } \\
22 \text { Dec }\end{array}$ & $\begin{array}{c}4 \\
8 \mathrm{Jan}- \\
28 \mathrm{Feb} \\
1972\end{array}$ & $\begin{array}{l}5 \\
13 \stackrel{\text { Mar- }}{1 \text { Jun }}\end{array}$ & $\begin{array}{c}6 \\
3 \text { June- } \\
22 \text { Aug }\end{array}$ & $\begin{array}{l}7 \\
12 \text { Sep- } \\
6 \text { Nov }\end{array}$ & $\begin{array}{c}8 \\
23 \text { Nov } \\
10 \text { Feb }\end{array}$ & $\begin{array}{l}9 \\
22 \text { Feb- } \\
11 \mathrm{Apr} \\
1973\end{array}$ \\
\hline $\begin{array}{l}\text { Area } 1 \\
\text { (Robinson Farm) }\end{array}$ & & & & - & & & & & \\
\hline Site 1 & 5.52 & 1.27 & 13.33 & 20.00 & 21.11 & 17.78 & 10.00 & 6.39 & 6.30 \\
\hline Site ${ }^{6} \bar{X}$ Area 1 & $\begin{array}{l}(31.56 \text { snap) } \\
4.98\end{array}$ & 2.22 & $\begin{array}{r}7.78 \\
10.56\end{array}$ & $\begin{array}{r}6.72 \\
13.36\end{array}$ & $\begin{array}{l}(0.0) \\
21.50 \\
21.31\end{array}$ & $\begin{array}{l}21.50 \\
19.64\end{array}$ & $\begin{array}{l}21.00 \\
15.50\end{array}$ & $\begin{array}{l}15.00 \\
10.70\end{array}$ & $\begin{array}{r}10.63 \\
8.46\end{array}$ \\
\hline $\begin{array}{l}\text { Area } 2 \\
\text { (Nelson Tract) } \\
\text { Site } 2 \\
\text { Site } 8 \\
\text { Site } 9 \\
\quad \bar{X} \text { Area 2 }\end{array}$ & 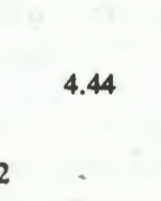 & 8.70 & 16.30 & (5.56) & $(0.0)$ & $(0.90)$ & $\begin{array}{r}17.00 \\
4.91 \\
10.96\end{array}$ & $\begin{array}{l}3.30 \\
8.00 \\
5.65\end{array}$ & $\begin{array}{r}9.50 \\
13.00 \\
11.25\end{array}$ \\
\hline $\begin{array}{l}\text { Area } 3 \\
\text { (Yankee Tank } \\
\text { Creek area) }\end{array}$ & & & & & & & & & \\
\hline $\begin{array}{l}\text { Site } 4 \\
\text { Site } 5 \\
\text { Site } 7 \\
\text { Site } 10 \\
\text { Site } 11\end{array}$ & 7.78 & $\begin{array}{l}2.78 \\
3.33\end{array}$ & $\begin{array}{l}11.67 \\
10.56\end{array}$ & $\begin{array}{r}8.89 \\
16.67\end{array}$ & $\begin{array}{l}22.22 \\
23.33\end{array}$ & $\begin{array}{l}\cdots \\
3.67 \\
3.29\end{array}$ & $\ddot{s}$ & 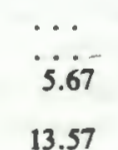 & $\ddot{2} \dot{ }$ \\
\hline $\begin{array}{l}\text { Site } 11 \\
\text { Site } 12\end{array}$ & 7.25 & 3.06 & 11.12 & 12.78 & 22.78 & $\begin{array}{l}3.48 \\
5.20^{*}\end{array}$ & 5.50 & $\begin{array}{r}13.57 \\
9.62\end{array}$ & 2.96 \\
\hline $\begin{array}{c}\text { Total trap } \\
\text { nights }\end{array}$ & 1,802 & 1,908 & 722 & 808 & 1,022 & 2,494 & 865 & 1,675 & 1,100 \\
\hline
\end{tabular}

months of 1972 and especially in March 1973, and colder in November and December 1972.

\section{Trapping procedures}

Within each sampling site one Sherman and one Fitch live trap (Fitch 1950) were placed at each of 45 trapping stations located at intervals of $\approx \mathbf{8} \mathrm{m}$, in irregularly shaped lines. The traps were prebaited with chicken scratch feed for 10 to 13 days. Trapping followed for 4 consecutive days or until a sample of 15 to 20 voles had been removed. Thus, at moderate-tohigh densities, 1 night of trapping was sufficient, while at low densities, even 4 days of trapping sometimes failed to produce an adequate sample for autopsy. Trapping was also terminated if no vole was captured during a given day. Only voles weighing $\mathbf{2 0}$ or more $\mathrm{g}$ were removed; voles of lighter body weight were counted but released.

Removal live trapping was begun in May 1971 and continued through March 1973 at biweekly intervals, depending on the vagaries of the weather. During the study, 4 sampling sites had to be abandoned because of low numbers of voles: site 2 apparently due to a combination of destruction of habitat by intruding cattle, to changes in plant species composition, and possibly to competition by hispid cotton rats ( $S$. hispidus); site 3 due to the inability of the population to replace numbers removed, presumably because the habitat was marginal; and the adjacent sites 4 and 5 due to habitat destruction after the city leased publicly owned land to cattle grazing. Each replacement site (numbers $6,7,8$, and 9) had a grid of standard size, $10 \times 10$ with 7.5-m intervals, and one Sherman trap per station. Table 1 shows the inclusive dates and number of trap nights on all sites.

At the time of capture, each vole was ear-tagged with a numbered fish fingerling tag, weighed, and examined for external reproductive information. Except during inclement weather, these procedures were done in the field. Animals were returned to the laboratory, sacrificed, and standard measurements made on each vole and a catalogue number assigned; the voles were then frozen until the day of autopsy.

\section{Autopsy procedure}

After thawing, each vole was autopsied and the reproductive data for males and females recorded as in Keller and Krebs (1970). For males, testes position (scrotal or abdominal), weight of paired testes, and condition of the tubules in the cauda epididymides are the important variables. Males were judged to be capable of breeding only if the epididymal tubules were convoluted, i.e., visible to the naked eye (Jameson 1950). For females, the variables used were: 


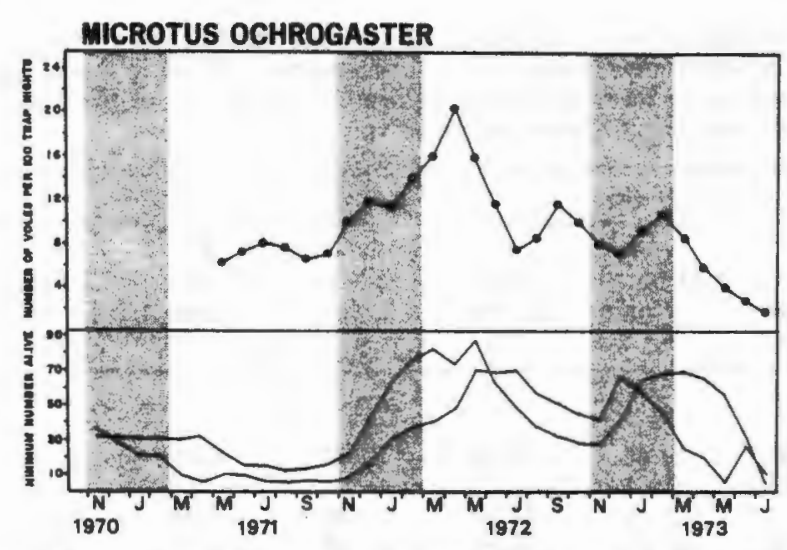

FIo. 1. Density changes for combined areas 1, 2, and 3 estimated by live-trap capture by month. Compared to minimum number alive on demographic grids A and B. Winter months are shaded.

1) pubic symphysis (closed, slightly open, open)

2) vaginal opening (perforate or imperforate)

3) uterus size-qualitative

a) thread-like, $\approx 1 / 2 \mathrm{~mm}$ wide

b) normal, $\approx 1$ to $2 \mathrm{~mm}$ wide

c) slightly enlarged, 3 to $6 \mathrm{~mm}$ wide (recently littered)

d) pregnant and enlarged

4) uterus weight, including embryos, if any (mg)

5) number of placental scars for right and left uterine horns

6) number of healthy embryos, plus number of resorbing embryos in each uterine horn

7) number of corpora lutea

8) number of corpora albicantia

The assessment of female breeding condition was based on 1 or more of several features:

1) nulliparous - no reproductive experience; pubic symphysis closed, nipples small, uterus threadlike to normal; no corpora lutea, corpora albicantia or placental scars.

2) primiparous-pubic symphysis slightly open or open, nipples medium to large, usually with some evidence of mammary gland development; uterus pregnant or with one set of placental scars of the same color and type; one set of either corpora lutea or corpora albicantia.

3) multiparous-pubic symphysis and mammary development similar to primiparous condition, but with uterus pregnant and with placental scars, or scars of 2 or more color/age classes, or with corpora lutea and corpora albicantia both present, or with corpora albicantia of 2 size classes.

\section{RESULTS}

\section{Population density}

All estimates were based on the number of voles captured during each trapping session of 1 to 4 days, regardless of size and fate of individuals. Thus, voles lighter than $20 \mathrm{~g}$ were included for purposes of estimating population density but were not a part of the reproductive assessment.

Table 1 shows the number of voles captured per 100 trap nights in each of the 3 areas. Each circuit represents $\approx 10 \mathrm{wk}$, the amount of time required to return to a given site. The estimate for each area is based on 1 to 3 sites sampled during the inclusive dates: Complete data are available for the first 3 circuits, but estimates cannot be made for area 2 during circuits 4,5 , and 6 because site 2 was disturbed by cattle in January of 1972 , and the vole populations did not recover in the spring and summer. Sites 8 and 9 permit density estimates to be made for area 2 during the last 3 circuits (from late summer 1972 through the spring of 1973).

Numerous studies (e.g., Elton 1942, Krebs 1964, Clough 1968) suggest that populations of microtines are synchronous over a geographical region. Our study supports this conclusion. Estimates of population numbers, whether determined by removal trapping or from direct enumeration on demographic grids (Gaines and Rose 1976), are in agreement that populations increased substantially through the autumn of 1971 and reached peak numbers the following spring. Figure 1 gives the density curve determined by the pooled monthly samples taken from removal sites and the number known to be alive on demographic grids $A$ and $B$ during the same months.

The disturbance of the several trapping sites midway through the study prevents the documentation of synchrony among the 3 study areas for all 9 circuits. However, there is evidence that the areas were changing density in the same manner, especially in the phase of increasing numbers. Spearman's rho $\left(r_{b}\right)$ is used to measure the degree to which densities of areas 1 and 3 are associated through circuit 5 (the maximum time interval between 2 areas without replacement). A highly significant correlation $\left(r_{4}=1.0, P=.01\right)$ exists between the 2 areas through the time of attainment of peak densities. It is of interest that not only are the trends in the same direction (Table 1) but that the number of voles taken per 100 trap nights is in close agreement. Area 2, during the increase phase, shows a rapid increase in numbers, and it appears that the population there might have reached peak numbers before areas 1 and 3 .

During circuits 7,8 , and 9 , the trapping data are complete for all 3 areas, although some site substitutions were made as previously described. Kendall's coefficient of concordance $(W)$ is used to measure the degree to which densities among the 3 study areas are associated for circuits 7,8 , and 9 . There is no synchrony among the 3 areas during the population decline $\left(W=0.386, \chi^{2}=0.1287, .95>P>.90\right)$. Area 1 apparently experienced a gradual decline in numbers during the summer of 1972 (Table 1) while densities 


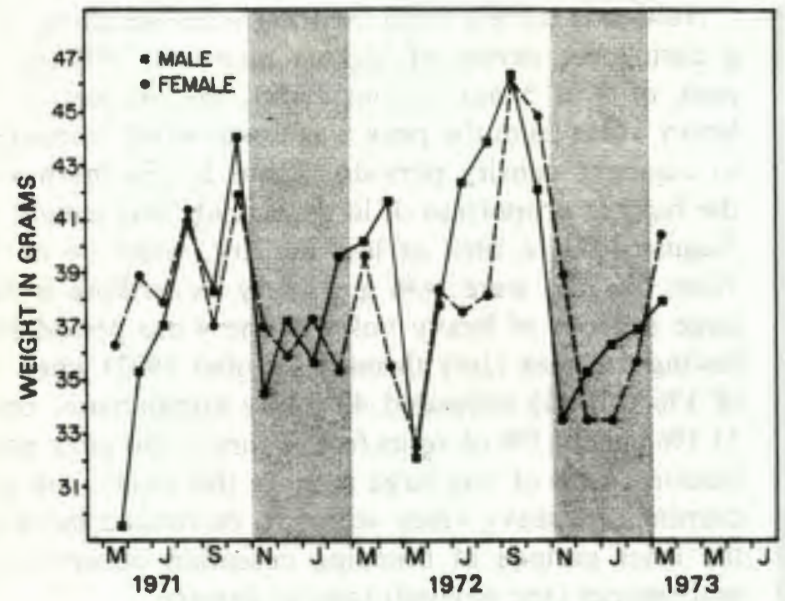

FIG. 2. Average body masses of $\delta$ and $q$ prairie voles by month. Weights of $\% ?$ corrected by subtracting weight of pregnant uteri. Winter months are shaded.

declined and then recovered in area 2 during the same period. The population in the site on area 3 was sustained at low numbers and then dropped further in the spring of 1973.

Although a satisfying documentation of the decline is missing as a consequence of the replacement of disturbed sites at the population peak, the significant correlation of areas 1 and 3 through the population peak permits the conciusion that the vole populations were synchronous through the time of attainment of peak densities in the late spring of 1972 , but that the declines differed in kind. Similar patterns of variable declines were noted on the 4 demographic grids which were monitored for the duration of this study (Gaines and Rose 1976) and have been noted elsewhere in studies which are well replicated (Keller and Krebs 1970, Gaines and Krebs 1971). The particular genetic or physiological qualities of the populations of voles, or the critical environmental factors, which cause some populations to drop quickly to very low numbers but permit others to decline rapidly and then recover, remain an enigma.

In summary, vole numbers increased in the fall of 1971 , through the winter, and reached peak densities in the spring of 1972 . Numbers then declined through the simmer and recovered and maintained moderate densities through the fall and winter, then resumed the decline in the spring of 1973.

\section{Sex ratios}

The structure of a mammalian population can influence the capacity for increase in polygamous or promiscuous species if sex ratios depart from unity. However, the trap-revealed sex ratio may be biased in favor of 1 sex, depending on the type of trap used (Myers and Krebs 1971). Martin (1956) found a significant deficiency of males in a 2-yr study using a type

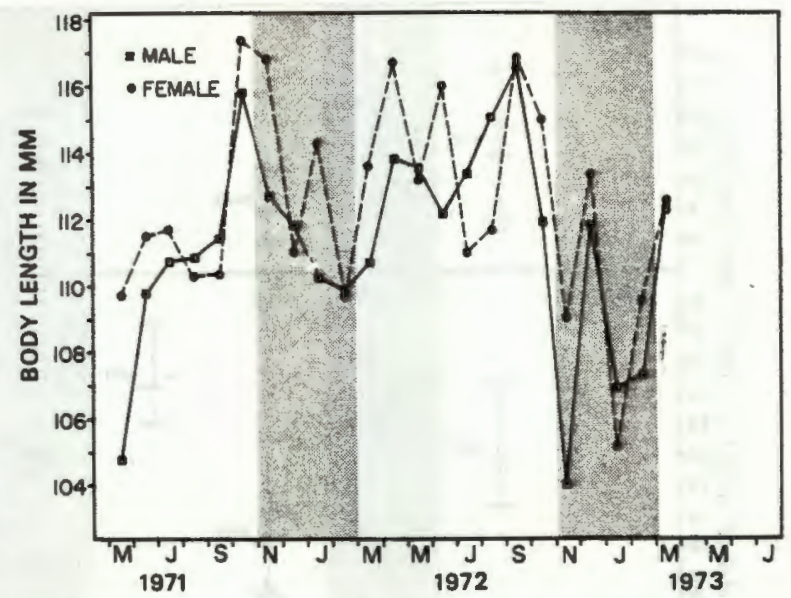

Fig. 3. Average body length measurements of $\delta$ and $q$ prairie voles by month. Body length equals total length minus tail length. Winter months are shaded.

of live trap designed by Fitch (1950); of the 817 voles trapped during Martin's study, only $45.02 \%$ were males, and during some months, the proportion of males caught was $<0.40$. Similarly, Greenwald (1956, p. 441) reported significantly fewer males of Microtus californicus taken by use of Museum Special breakback traps. However, Keller (1968), also using snap traps, caught a slight, nonsignificant excess of males of $\boldsymbol{M}$. ochrogaster and $M$. pennsylvanicus.

In this study, nearly 800 voles were examined; of these 98 were taken by Museum Special traps and the rest by either Fitch or Sherman live traps. Each type yielded a slight but nonsignificant deficiency of males (snap: $\chi^{2}=2.227, .5>P>.1$; live: $\chi^{2}=0.204, .9>P$ $>.5)$. Of all prairie voles examined in this study, $48.36 \%$ were males. We also tested for deviation from 1:1 sex ratio between areas, seasons, and peak vs. increase or decline populations, but again no significant differences were found.

\section{Body size changes}

Previous studies of fluctuating species of microtine rodents suggest that changes in body mass and body length accompany changes in density. Specifically, adults of peak populations have been found to be larger than adults of increasing or declining populations (Kalela 1957, Chitty and Chitty 1962, Keller and Krebs 1970, Krebs and Myers 1974). We would expect the Kansas prairie voles to follow a pattern similar to that observed by Keller and Krebs (1970) in Indiana voles, where large animals, arbitrarily defined as those with a mass $>46 \mathrm{~g}$, were present during the peak but less numerous during early increase or late decline or low phases of the cycle. However, we observed no tendency of high average body masses to be associated with peak density (Fig. 2). Instead, strong seasonal effects were noted, with the average mass of both sex- 


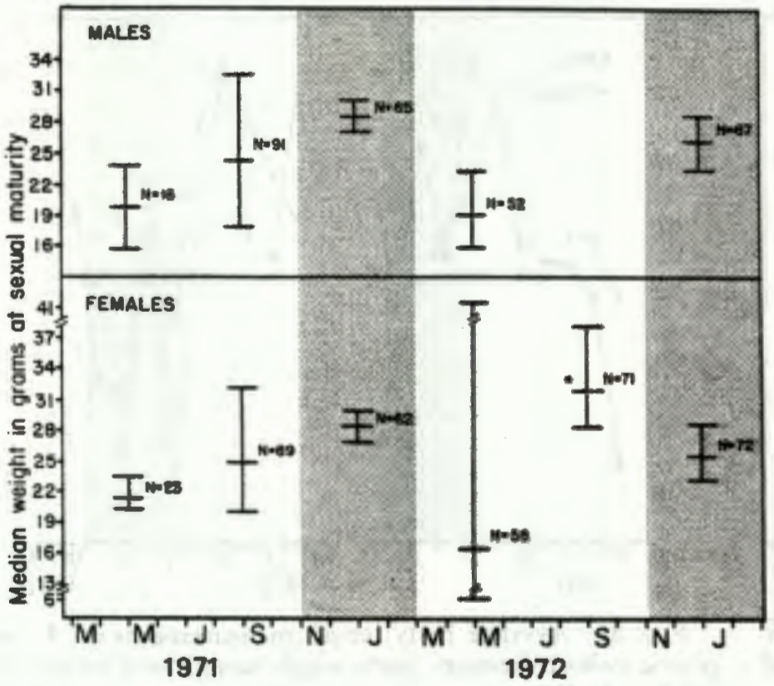

F1G. 4. Median mass at sexual maturity, with $95 \%$ confidence limits. $N$ is the number of individuals from which the estimate was taken. An asterisk indicates that the confidence limits are approximated; the dashed line is an estimate of the median weight. Winter months are shaded. See text for explanation of sample of $\delta \delta$ from July-October 1972.

es lowest in the winter months and increasing sharply in late winter, probably due to growth of overwintering adults. (Masses of pregnant females were adjusted by subtracting the mass of the uteri. All individuals with a mass of $20 \mathrm{~g}$ or more were included in the sample of a given month.) That the drop in average weight of individuals in the population peak is partly due to recruitment of young into the trappable population is supported by the observed flush of small, untagged voles on the demographic grids during May 1972, a month of peak density. Throughout the remaining warmer months the average weight increased.

There is no difference in the weights of males and females in this study $\left(\chi^{2}=9.868,11 \mathrm{df}, P>.75\right)$, and the sexes have been pooled in the following analyses. Using both 3 and 5 mo as the period of peak numbers. the mean weights of the population from the peak period are similar to, but slightly less than, those of populations preceding and following the period of greatest numbers. Highest numbers were achieved in the months of March, April, and May 1972 (Fig. 1).
Neither is there a trend favoring voles weighing $>46$ $\mathrm{g}$ during the period of highest numbers. Whether a peak of 3 or $5 \mathrm{mo}$ is considered, the proportion of heavy voles from the peak was lower when compared to adjacent density periods (Table 2). Furthermore, the highest proportion of large animals was caught in August 1971, a time of low density, when 36 of 98 voles $(36.7 \%)$ were $>46 \mathrm{~g}$. Nearly as striking is the large number of heavy voles in the 4-mo period following the peak (July through October 1972) when 38 of 136 (27.9\%) exceeded $46 \mathrm{~g}$. By comparison, only $11.1 \%$ and $14.1 \%$ of voles from 3- and 5-mo peak populations were of this large size. In this study, the occurrence of heavy voles seems to be related more to the brief periods of breeding cessation observed in midsummer (see beyond) than to density.

Similar analyses of body length distributions indicate a trend toward the patterns of change more like those reported for other cyclic species, i.e., of large (here longer) voles in the months of the population peak. The distribution of body length (total length minus tail length) by month, given in Fig. 3, shows a strong association with body mass distributions, except for the months of the population peak, when the sharp drop in body mass of late. spring voles is not paralleled by a corresponding drop in body length. Indeed, body length is slightly longer $(1.3 \mathrm{~mm}$ for males and $2.6 \mathrm{~mm}$ for females) than for voles collected in the same months during nonpeak years. The greatest effect of density appears to be in the body lengths of voles of the 2 winters; both males and females were $2.6 \mathrm{~mm}$ longer in the winter preceding the population peak. Neither of these comparisons is significantly different (males, $F=0.907$, df $=1,131, .50>P>.25$; females, $F=0.693$, df $=1,116, .50>P>.25$ ). (Overall, there is likewise no difference in body length distributions of males and females, $\chi^{2}=10.681,11 \mathrm{df}$, $P=.5$ ). In this study, then, voles from peak populations are somewhat lighter but slightly longer compared to voles of adjacent density periods. They are not significantly different in size from voles taken at the same season in nonpeak years.

\section{Sexual maturity}

Microtines, with their ever-growing cheek teeth, are among the most difficult of mammals for which to de-

TABLE 2. Mean body weights of combined $\delta$ and $q$ samples collected during periods relating to density. Three- and 5-mo periods of peak density are compared. Female weights are adjusted by subtracting the uterus weight of pregnant individuals. Inclusive dates for the periods relating to density are given

\begin{tabular}{lccccc}
\hline Phase in density cycle & Mean mass $(\mathrm{g})$ & $N$ & No. $>$ 46 $\mathrm{g}$ & Percent $>\mathbf{4 6} \mathrm{g}$ & Calendar dates \\
\hline Peak, 3-mo duration & 35.73 & 63 & 7 & 11.11 & Mar-May 1972 \\
Peak, 5-mo duration & 36.90 & 149 & 21 & 14.09 & Feb-Jun 1972 \\
Prepeak, 3-mo duration & 38.27 & 370 & 61 & 16.49 & May 1971-Feb 1972 \\
Prepeak, 5-mo duration & 38.37 & 327 & 56 & 17.13 & May 1971-Jan 1972 \\
Postpeak, 3-mo duration & 38.90 & 348 & 56 & 16.09 & Jun 1972-Mar 1973 \\
Postpeak, 5-mo duration & 39.03 & 305 & 47 & 15.41 & Jul 1972-Mar 1973 \\
\hline
\end{tabular}


TABLE 3. Number of $q q$ pregnant and not pregnant by parity class, pregnancy rates defined by parity and weight, and percent females $>19 \mathrm{~g}$ not breeding, by 4 mo periods. (PP $=$ primiparous, $M P=$ multiparous, NP $=$ nulliparious)

\begin{tabular}{|c|c|c|c|c|c|c|c|c|}
\hline \multirow[b]{2}{*}{ Trapping period } & \multicolumn{2}{|c|}{ Pregnant } & \multicolumn{2}{|c|}{ Not pregnant } & \multirow[b]{2}{*}{ NP } & \multicolumn{2}{|c|}{ Percent pregnant } & \multirow[b]{2}{*}{ NP (\%) } \\
\hline & PP & MP & PP & MP & & $\mathbf{P P}+\mathbf{M P}$ & $\geqslant 20 \mathrm{~g}$ & \\
\hline May-Jun 1971 & 5 & 9 & 7 & 1 & 1 & 63.6 & 60.9 & 4.3 \\
\hline Jul-Oct 1971 & 19 & 22 & 22 & 16 & 19 & 51.9 & 41.8 & 19.4 \\
\hline Nov 1971-Feb 1972 & 22 & 11 & 11 & 7 & 10 & 64.7 & 54.1 & 16.4 \\
\hline Mar-Jun 1972 & 19 & 14 & 12 & 6 & 6 & 64.7 & 57.9 & 10.5 \\
\hline JuJ-Oct 1972. & 18 & 12 & 13 & 10 & 18 & 56.6 & 42.3 & 25.4 \\
\hline Nov 1972 -Feb 1973 & 12 & 9 & 19 & 15 & 14 & 38.2 & 30.4 & 20.3 \\
\hline Mar 1973 & 7 & 5 & 2 & 3 & 0 & 70.6 & 70.6 & 0.0 \\
\hline
\end{tabular}

termine ages. Several methods have been attempted, using cranial measurements or eye lens weights (e.g., Hoffmeister and Getz 1968) for voles of known ages, but none is easily applied. We follow the method of Krebs et al. (1969) of using body weight rather than chronological age for determining sexual maturity, and a median weight at sexual maturity-is calculated using the methods of Leslie et al. (1945, and summarized in Keller and Krebs 1970).

The median weight at sexual maturity for the voles examined in this study is given in Fig. 4: No median weight at sexual maturity could be calculated for the males in the July-October 1972 sample because all 64 individuals examined, regardless of size, were in reproductive condition (median mass $43.0 \mathrm{~g}, 95 \%$ confidence limits $41.72-44.77, n=64$ ). Similarly, for the samples taken in March 1973, all individuals of both sexes were mature (males: median 38.0 , 95\% confidence limits $35.04-40.70, n=15$; females: median $40.0,95 \%$ confidence limits $36.28-44.36, n=17$ ). Several trends are evident from these data:

1) both sexes mature at about the same weight, except during the months of the population peak (March-June 1972), when there was high variability and a trend toward reduction in the median weight of sexually mature females;

2) development time is prolonged during the winter months, especially in the winter preceding the peak densities (November 1971-February 1972); and

3) a considerable upward shift in the weight at sexual maturity of females occurred early in the population decline (late summer of 1972), with the median mass increasing to $\approx 32 \mathrm{~g}$ during this time.

\section{Pregnancy rate}

In an iteroparous species such as Microtus the potential for exponential population growth is ever-present. Females, once mature, are capable of having litters every 21-22 days, for postpartum breeding commonly occurs within $24 \mathrm{~h}$ (Richmond and Conaway 1969). Pregnancy rate, the proportion of mature females having visible embryos, may have profound effects on the rate of increase, especially in defining the amplitude of the density curve during the increase phase. Microtus embryos become visible at the 6th day (Hoffmann, 1958), giving a maximum observable pregnancy rate of $15 / 21$, or 0.71 . The higher rates reported by Keller and Krebs (1970) and observed in some monthly samples in this study may be due to synchrony of reproduction. (The pattern appears too frequently to be attributable to sampling error.)

Keller and Krebs (1970) have discussed the major difficulty in defining pregnancy rates, first recognized by Leslie et al. (1952); namely, which individuals to include as potentially mature. One approach is to include all females above some minimum mass or length; the other is to consider only females with corpora lutea or corpora albicantia. The first approach ignores the changes in mass at sexual maturity as seen in Fig. 4. The second avoids this problem but becomes tautological by stating that only fernales of demonstrated reproductive capacity are mature. We shall compare pregnancy rates using both approaches.

In the winter prior to the initiation of this study, 1970-1971, no female in late pregnancy was observed, and there was a marked reduction in the proportion of females with perforate vaginae on the demographic grids (Gaines and Rose 1976). Fitch (1957) found the occurrence of perforate vaginae to be roughly correlated with pregnancy rate. Using mark-recapture methods, other studies in eastern Kansas (Jameson 1947, Martin 1956, Fitch 1957) indicate that, in most years, there is no (or at best, occasional) breeding in the months of December and January, with the Iatter study showing a delay until April in 1 yr. A breeding season beginning in February and ending in November is therefore suggested for eastern Kansas populations of prairie voles. However, in our study, there was no clearly defined breeding season, and a substantial percentage of pregnant females was collected each season, with the lowest frequencies occurring in July of both years (see below). There was also a slight depression in the pregnancy rate during the winter of the population decline (November 1972 to February 1973).

In our study, reproductive information was obtained for all voles with a mass of $20 \mathrm{~g}$ or more. Prairie voles of lesser mass have rarely been reported as reproductives in the literature (see below). No female with a 


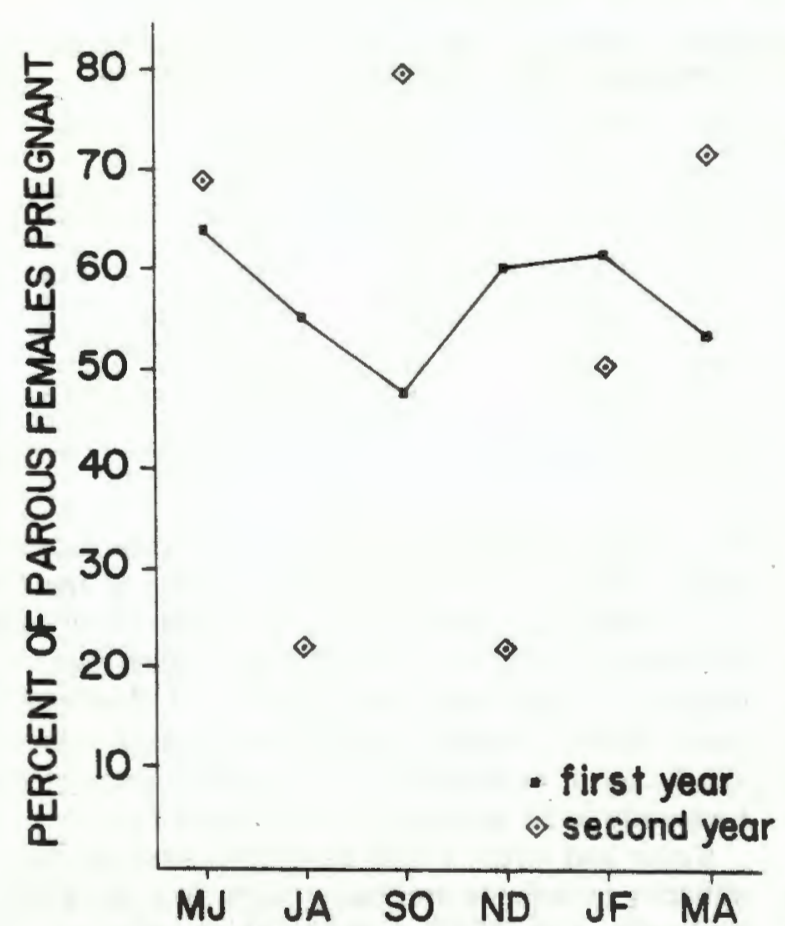

F1G. 5. Percentage of parous $q \%$ pregnant for bimonthly periods. First year is MJ (May-June) 1971 through MA (March-April) of 1972, 2nd year is May-June 1972 through March 1973.

mass $<22.6 \mathrm{~g}$ was observed to be pregnant, so the pregnancy rates defined on the basis of $20 \mathrm{~g}$ body mass are conservative.

In the absence of a breeding season, data have been lumped into 4-mo blocks and examined for differences in the pregnancy rates within and among blocks using the chi-square test of homogeneity. Table 3 shows the number of females in each parity class and the pregnancy rates defined by parity and weight.

Heterogeneity of pregnancy rate is observed within the 4-mo blocks including the months of July as well as December of 1972 . Whether defined on parity or mass criteria, a highly significant heterogeneity exists for the block containing the July 1971 sample (parity, $x^{2}=31.19,3 \mathrm{df}, P<.005$; weight, $x^{2}=24.10,3 \mathrm{df}$, $P<.005$ ). In 1972 , a highly significant heterogeneity is again observed for the same months, July through October (on parity criteria, $\chi^{2}=17.38,3 \mathrm{df}, P<.005$; on weight criteria, $\chi^{2}=34.16,3 \mathrm{df}, P<.005$ ). Although the July sample of parous females is small, the grid yielding these animals was trapped intensively during the entire month; 9 nulliparous females between 31 and $42 \mathrm{~g}$, only 3 of 32 females with perforate vaginae, and none in late pregnancy suggest a general cessation of breeding activity. The same pattern appears to have continued into August as well.

During December 1972, only 2 of 18 parous females were observed to be pregnant, resulting in significant heterogeneity within the November 1972 to February 1973 block (on parity criteria, $\chi^{2}=9.81,3 \mathrm{df}, .025$ $>P>.01$; on weight criteria, $x^{2}=9.71,3 \mathrm{df}, .025>$ $P>.01$ ).

Comparisons made among the 6 4-mo blocks showed significant heterogeneity for both parity $\left(x^{2}\right.$ $=11.25,5 \mathrm{df}, .05>P>.025)$ and weight $\left(x^{2}=14.88\right.$, $5 \mathrm{df}, .025>P>.01$ ) criteria. Removal of the July samples and that of December 1972 from the analysis results in the loss of heterogeneity in both instances (parity, $x^{2}=2.93,5 \mathrm{df}, .9>P>.5$; weight, $x^{2}=$ 4.49, $5 \mathrm{df}, .5>P>.1$ ).

Because July (and in $1 \mathrm{yr}$, also August) appeared to have the lowest, and April and October the highest, pregnancy rates, we plotted the pregnancy rates from both years by bimonthly groups to examine more closely for seasonal effects (Fig. 5). Viewed this way, pregnancy rates for the first 6 calendar mo are less variable between years compared to the latter half year. Related to density, pregnancy rate was much more uniform during the months of increase and peak of the population; by contrast, in the phase of declining numbers, pregnancy rate was much more variable, due primarily to the extension of the July depression into August and the shutdown in December as well. These differences, plus the higher pregnancy rate in September-October of the recovery period, may be effects related to density itself.

These results suggest to us that:

1) pregnancy rates were relatively constant throughout the study, except for the 3 unexplained, brief lapses into nonreproductive states;

2) despite having set the lower weight limit well below the observed lower limit of pregnant females, pregnancy rates differ little, if any, whether defined by parity or weight criteria;

3) the proportion of subadult and adult females in reproductive state approached the maximum observable frequency (.71) in all seasons except during the winter following the population peak. Even during this period, $38.2 \%$ of the parous females were pregnant:

4) the variation in pregnancy rate in the first 6 mo of the increase phase may relate more to density than to seasonal effects; and

5) the variation in pregnancy rates increased during the period of declining numbers.

\section{Number of embryos}

Among the factors which can influence the number of embryos produced by a female are season, maternal weight, previous reproductive experience (or parity) and density of the population. Sadleir (1969, Ch. 15) has summarized much of the recent literature on seasonal and the related latitudinal effects of litter size (=embryo count) in small mammal populations. No general statement can be made which will apply to all microtine populations, as indicated by the study of 
Hoffmann (1958), who found that in $M$. californicus, litter size increases as the breeding season continues, whereas in $\boldsymbol{M}$. montanus, litter size is greatest early in the season and progressively declines thereafter. This suggests that litter size may be related to the quality of the food supply available to females early and late in the breeding season. Lidicker (1973) reported litter size in $M$. californicus to decline steadily beyond the months of February to April. Fitch (1957) noted that litter size in $\boldsymbol{M}$. ochrogaster was positively correlated with the peak of the breeding season. The usual explanation for large litters at the peak of the breeding season is that the proportion of large females is greatest at that time. To test whether changes in body size were responsible for variation in litter size in our study, we first computed the correlation coefficient for the number of embryos and body mass of females. We find no significant correlation between embryo count and body mass for either primiparous $(r=.145, n=100)$ or multiparous $(r=.013, n=81)$ females. Nor was there a significant correlation between corpora lutea count and body mass for either parity class $(r=.186, .1>P>.05$, and $r=.051)$. Had there been a significant correlation, it would have been necessary to employ regression analysis to remove the variation contributed by changes in body mass (see Keller and Krebs 1970). However, in this instance, a consideration of means is sufficient, because maternal size is not contributing to the observed variation in litter size or corpora count.

Next we divided the pregnant females into the 4-mo periods and then tested for difference in mean number of embryos between primiparous and multiparous females. There is no difference in the observed mean number of embryos of these 2 groups $(F=0.002$, df $=1,179)$. Thus parity does not affect litter size either, and these 2 classes can be pooled for further analysis.

Pregnant females were then grouped into periods related to density, using the 5 mo from February through June 1972 as the population peak (Table 4). There is a significant difference among means of these density periods $(F=9.992$, df $=2,178, P<.001)$. Specifically, the number of embryos is significantly lower during the prepeak period $\bar{X}=3.04)$ compared to means of either the peak $\bar{X}=3.69 ; F=9.783$, df $=1,116, .005>P>.001)$ or postpeak $\overline{(X}=3.70 ; F$ $=13.216$, df $=1,134, P<0.001$ ) periods. Embryo numbers for the latter 2 periods do not differ $(F=$ 0.0016 , df $=1,106$ ).

In an attempt to examine seasonal effects more closely, the 181 pregnant females were then divided into 2-mo periods and comparisons made both between similar periods of different years and between adjacent bimonthly periods. There are no differences among all comparisons of embryo counts for bimonthly periods between years (Fig. 6). For example, the mean number of embryos for May and June of the population peak (1972) was not significantly different

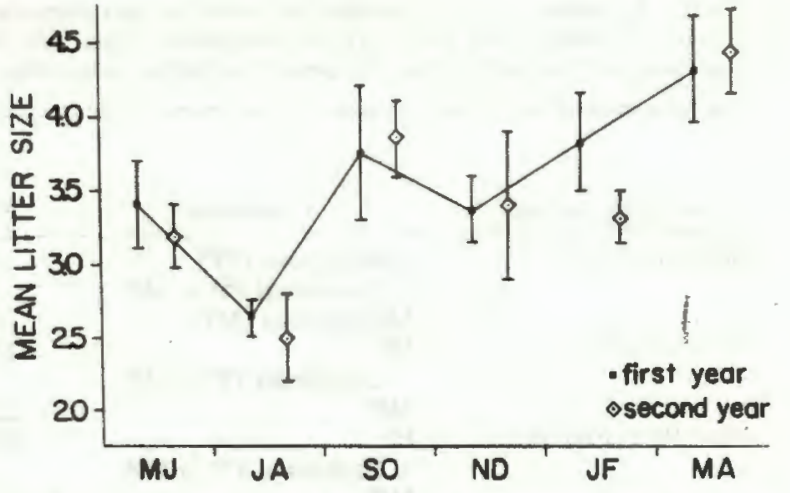

FIG. 6. Mean litter size ( $\approx$ embryo counts) and standard errors for bimonthly periods. First year and months as in Fig. 5.

from the mean number of the previous May-June sample. This analysis also suggests that the significant increase observed in the March 1973 sample is merely a seasonal effect, for the mean number of embryos is the same as was observed in the March-April 1972 sample. Fitch (1957) and Jameson (1947) also observed that litter size is largest in March. With respect to embryo count ( $\approx$ litter size) there appears to be a strong seasonal component that may relate little to phase in the cycle (Fig. 6).

Comparisons of mean embryo number between adjacent bimonthly samples show the July-August 1971 sample to have significantly lower embryo numbers compared to both the preceding $(F=10.028$, $\mathrm{df}=$ $1,43, .005>P>.001)$ and the following $(F=12.949$, df $=1,39, P<.001)$ bimonthly periods. A similar significant drop in mean embryo number occurred during the months of the population peak; the March-April sample averaged 4.33 embryos, and the May-June sample, $3.17(F=6.993$, if $=1,30, .025>P>.01)$. Another large, but nonsignificant, drop in embryo number followed during the ensuing 2-mo period, making the mean number of embryos in the July-August samples similar between years. Finally, the mean number of embryos in March 1973 was significantly higher than the preceding bimonthly period $(F=$ 11.843 , df $=1,26, .005>P>.001$ ). As there are no differences between years for samples including the month of March, this increase is due to the slight, but nonsignficant, depression in mean embryo number during January-February of 1973 compared to the January-February sample of 1972.

In summary, we find no association between either maternal mass or parity and litter size. Marked seasonal effects on litter size were observed, with bimonthly samples including the month of March averaging significantly greater numbers of embryos per female and the July-August samples, substantially fewer embryos in both years. Other bimonthly samples had uniform embryo production. Related to density, litter size was significantly lower in the prepeak 
TABLE 4. Means of body weight and embryo and corpora lutea counts for primiparous (PP) and multiparous (MP) $\$ 9$ for 4-mo periods. Also given are the weighted means for the combined samples of each period, together with the standard errors, and similar values for periods relating to density

\begin{tabular}{|c|c|c|c|c|c|c|c|c|c|}
\hline Sampling period & Condition & $\boldsymbol{N}$ & & $\begin{array}{l}\text { Mean } \\
\text { body } \\
\text { mass (g) }\end{array}$ & SE & $\begin{array}{c}\text { Embryos } \\
(\bar{x})\end{array}$ & SE & $\begin{array}{l}\text { Corpora } \\
\text { lutea } \\
(\bar{x})\end{array}$ & SE \\
\hline May-Jun 1971 & $\begin{array}{l}\text { Primiparous (PP) } \\
\text { Combined PP }+ \text { MP } \\
\text { Multiparous (MP) }\end{array}$ & $\begin{array}{l}4 \\
8\end{array}$ & 12 & $\begin{array}{l}35.85 \\
39.60 \\
41.46\end{array}$ & 2.09 & $\begin{array}{l}3.00 \\
3.42 \\
3.63\end{array}$ & 0.29 & $\begin{array}{l}3.00 \\
3.42 \\
3.63\end{array}$ & 0.29 \\
\hline Juk-Oct 1971 & $\begin{array}{l}\text { PP } \\
\text { Combined PP + MP }\end{array}$ & $\begin{array}{l}19 \\
22\end{array}$ & 41 & $\begin{array}{l}43.25 \\
43.78 \\
44.24\end{array}$ & 1.11 & $\begin{array}{l}2.89 \\
2.83 \\
2.77\end{array}$ & 0.14 & $\begin{array}{l}3.16 \\
3.12 \\
3.09\end{array}$ & 0.15 \\
\hline Nov 1971-Feb 1972 & $\begin{array}{l}\mathbf{P P} \\
\text { Combined PP }+\mathbf{M P}\end{array}$ & $\begin{array}{l}22 \\
11\end{array}$ & 33 & $\begin{array}{l}38.06 \\
39.09 \\
41.18\end{array}$ & 1.11 & $\begin{array}{l}3.77 \\
3.61 \\
3.27\end{array}$ & 0.21 & $\begin{array}{l}4.36 \\
4.09 \\
3.55\end{array}$ & 0.21 \\
\hline Mar-Jun 1972 & $\begin{array}{l}\text { PP } \\
\text { Combined PP + MP }\end{array}$ & 18 & 32 & $\begin{array}{l}36.23 \\
38.81 \\
42.13\end{array}$ & 1.41 & $\begin{array}{l}3.61 \\
3.50 \\
3.36\end{array}$ & 0.22 & $\begin{array}{l}4.00 \\
3.94 \\
3.86\end{array}$ & 0.25 \\
\hline Jul-Oct 1972 & $\begin{array}{l}\mathbf{P P} \\
\text { Combined PP }+ \text { MP }\end{array}$ & $\begin{array}{l}18 \\
12\end{array}$ & 30 & $\begin{array}{l}44.49 \\
44.67 \\
44.90\end{array}$ & 1.38 & $\begin{array}{l}3.50 \\
3.67 \\
3.92\end{array}$ & 0.24 & $\begin{array}{l}3.83 \\
4.07 \\
4.42\end{array}$ & 0.23 \\
\hline Nov 1972-Feb 1973 & $\begin{array}{l}\text { PP } \\
\text { MP }\end{array}$ & $\begin{array}{r}12 \\
9\end{array}$ & 21 & $\begin{array}{l}33.13 \\
36.90 \\
41.91\end{array}$ & 1.52 & $\begin{array}{l}2.92 \\
3.33 \\
3.89\end{array}$ & 0.17 & $\begin{array}{l}3.25 \\
3.76 \\
4.44\end{array}$ & 0.30 \\
\hline \multirow[t]{2}{*}{ Mar 1973} & $\underset{\text { MP }}{\text { Combined PP + MP }}$ & $\begin{array}{l}7 \\
5\end{array}$ & 12 & $\begin{array}{l}39.71 \\
40.37 \\
41.28\end{array}$ & 2.68 & $\begin{array}{l}4.29 \\
4.42 \\
4.60\end{array}$ & 0.29 & $\begin{array}{l}5.14 \\
4.92 \\
4.60\end{array}$ & 0.50 \\
\hline & & & lot & density & & & & & \\
\hline $\begin{array}{l}\text { May 1971-Jan } 1972 \\
\text { prepeak period } \\
\text { Feb-Jun } 1972\end{array}$ & Combined PP + MP & 73 & & 42.00 & 0.80 & 3.04 & 0.11 & 3.30 & 0.23 \\
\hline $\begin{array}{l}\text { peak period } \\
\text { Jul 1972-Mar } 1973\end{array}$ & Combined PP + MP & 45 & & 38.59 & 1.16 & 3.69 & 0.19 & 4.20 & 0.21 \\
\hline postpeak period & Combined PP + MP & 63 & & 41.25 & 1.05 & 3.70 & 0.15 & 4.13 & 0.18 \\
\hline
\end{tabular}

period compared to either the peak or postpeak populations. Thus, although an increase in litter size may have contributed in some measure to the attainment of peak densities, the population decline cannot be explained by a reduction in litter size. Changes in the levels of natality in the population are not sufficient to explain the changes in density.

\section{Prenatal mortality}

Reduction of realized litter size, given a constant ovulation rate, could result from the failure of a percentage of viable ova to be fertilized or from the intrauterine death of 1 or more developing embryos. Losses of the first type, termed preimplantation mortality, might result from mating with a male of reduced fertility or from a qualitative inadequacy of the uterine mucosa. Such losses might, therefore, be greatest at the beginning or end of the breeding season of males, or in primiparous or very old fernales. Mortality of the second type, called postimplantation loss, results from the genetic or developmental death of an embryo which had successfully established a placenta in the uterus. If density has any detrimental effects on reproduction, we hypothesized that postimplantation mortality will be greatest during periods of high numbers.
We tested 2 hypotheses with respect to prenatal mortality, that there are no significant differences in the proportion of: (1) females showing loss of ova or embryos during the population cycle; and (2) total ova or embryos lost during different phases of the population cycle. Pre- and postimplantation mortality are considered separately.

\section{Preimplantation losses}

In Microtus, ovulation occurs $\approx 10 \mathrm{~h}$ after copulation (Richmond 1967), although Greenwald (1956) reported that, in $M$. californicus at least, not all follicles rupture simultaneously. A mature ovum rapidly increases from 500 or 600 to $900 \mu \mathrm{m}$ between copulation and ovulation. After release of the ovum, the remnants of the follicle grow rapidly into a corpus luteum which, by late pregnancy, is 1.5 to $2.0 \mathrm{~mm}$ in diameter. Thus the number of ova released from an ovary can be approximated by counting the number of easily detectable corpora lutea (except in $\boldsymbol{M}$. californicus, which produces accessory corpora lutea). Any difference between the numbers of corpora lutea and implantation sites is attributable to preimplantation loss. Such an assessment is conservative because of the possibility of:

1) underestimating the number of corpora lutea us- 
TABLE 5. Prenatal mortality in Microtus ochrogaster for 4-mo periods. Peak density achieved in February through June 1972

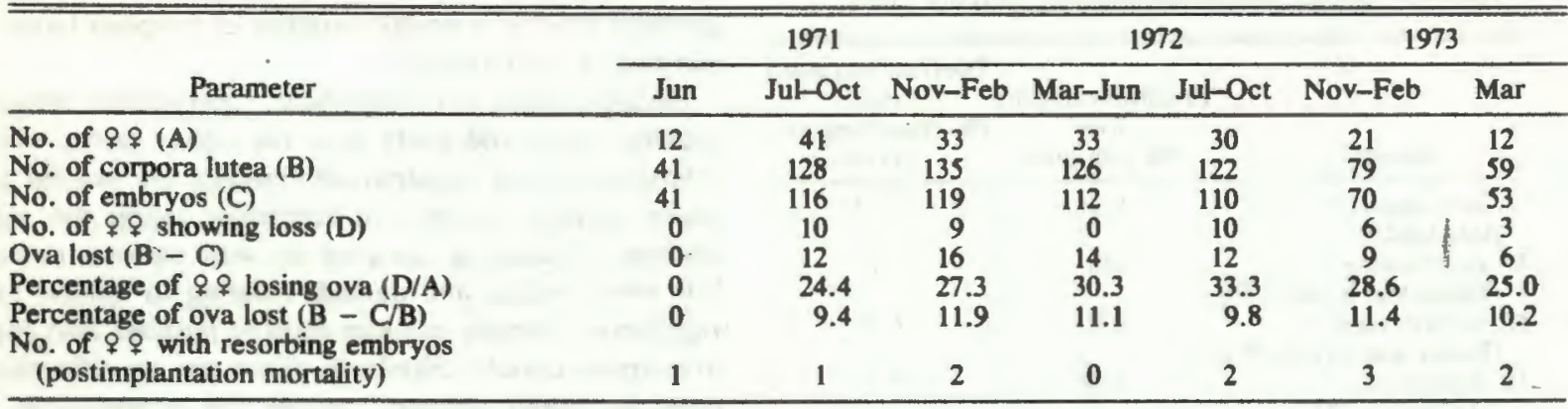

ing a dissecting microscope compared to histological sectioning methods. Snyder (1969) reported an error of $1.6 \%$ for $M$. pennsylvanicus;

2) of polyovuly, the release of more than 1 ovum from a given follicular size (Brambell 1948); and

3) twinning, and the possible consequent sharing of the same implantation site.

In this study, ovaries- were examined with a dissecting microscope. Three cases of possible polyovuly or twinning were noted, 2 in the June 1971 sample (each having 1 less corpus luteum than embryo) and a third in May 1972 in which 6 embryos and 4 corpora lutea were observed. Because the source of the error cannot be determined, these 3 females have been omitted from the analysis of prenatal effects.

Table 5 summarizes the preimplantation mortality data. Four-mo blocks were examined for homogeneity using the log-likelihood chi-square method (Bliss 1967). No significant differences were found, either in the proportion of females showing partial loss of ova or in the proportion of ova lost. Heterogeneity among 4-mo blocks was considered as well; again, there was no difference observed at the .05 level of significance. Overall, $25.0 \%$ of females showed loss, and $9.5 \%$ of ova were lost to preimplantation mortality.

\section{Postimplantation losses}

Any grossly smaller embryos or placental scars without accompanying mammary development are indications of partial or complete postimplantation mortality. Although some of the small embryos may survive until birth, the methods used also are conservative because some loss will occur before any embryo is large enough to be visible (about day 6), and midterm losses may go unnoticed when implantation sites are obliterated after the enlargement of adjacent placentae. Table 6 shows the proportion of pregnant females losing embryos and the proportion of ova lost through resorbed or aborted embryos in this study and those of Hoffmann (1958), Greenwald (1956), Keller and Krebs (1970) and Lidicker (1973). In the present study, only 10 females (5.35\%) had 1 embryo of reduced size, and only 10 embryos (1.55\%) were lost to postimplan- tation mortality. The sample is too small to test for seasonal or density effects, but of the 10,3 were observed before, 1 during, and 7 after the population peak, suggesting a negative density effect if any (Table 5). Additionally, 1 primiparous female had 1 normal embryo near term in 1 uterine horn and a placental scar in the other. Since no corpora albicantia were evident, the scar probably resulted from the abortion or resorption of the embryo. It is likely that this female, caught in September 1972 also experienced postimplantation mortality. One possible case of the loss of an entire litter and 3 probable cases of transuterine migration were also observed.

Both this study and that of Keller and Krebs (1970) support the null hypothesis of prenatal mortality related to period in the cycle, i.e., neither shows any effect of density on either pre- or postimplantation loss. Nor are there any differences in this study in preimplantation mortality between primiparous versus multiparous females based on periods of greatest breeding activity (March, April, September, and October), least breeding activity (November through February) and intermediate breeding activity (April through July) $\left(\chi^{2}=0.324,5 \mathrm{df}, P>.995\right)$. In fact, the lowest percentage of ova lost was in primiparous females of the late spring and summer (April through July) among low mass $(\bar{X}=36.69 \mathrm{~g})$ females. Thus it would seem that preimplantation losses are not greatest among naive females. Hoffmann (1958) has pointed out that few adults live long enough to show any symptoms of aging; consequently, the effects of old age on preimplantation loss, while they may be real, are of little concern in the population sense and in fact cannot be detected in Microtus.

Eight of 11 probable cases of postimplantation mortality were among primiparous females, but only 1 , a $30-\mathrm{g}$ individual, had a mass $<40 \mathrm{~g}$. The expectation that the frequency of spontaneous abortion will be greatest in young, barely mature females is not fulfilled in this instance either. It is unlikely that low fertility in males contributes much to preimplantation mortality, because no seasonal quiescence of testes was observed in this study (see below). 
TABLE 6. Summary of the loss of ova and embryos in 4 species of Microtus from North America. The asterisk (*) refers to species with supernumerary corpora lutea

\begin{tabular}{|c|c|c|}
\hline Species & $\begin{array}{c}\text { Preimplantation } \\
\text { loss } \\
\text { (\% ova lost) }\end{array}$ & $\begin{array}{l}\text { Postimplantation } \\
\text { loss } \\
\text { (\% resorbing em- } \\
\text { bryos) }\end{array}$ \\
\hline $\begin{array}{l}M \text {. ochrogaster } \\
\text { (this study) }\end{array}$ & 9.46 & 1.55 \\
\hline $\begin{array}{l}\text { M. ochrogaster } \\
\text { (Keller and Krebs 1970) }\end{array}$ & 6.6 & 7.0 \\
\hline $\begin{array}{l}\text { M. pennsylvanicus } \\
\text { (Keller and Krebs 1970) }\end{array}$ & 9.0 & 6.4 \\
\hline $\begin{array}{l}\text { M. montanus } \\
\text { (Hoffmann 1958) }\end{array}$ & 5.86 & 3.25 \\
\hline $\begin{array}{l}M \text {. californicus } \\
\text { (Hoffmann 1958) }\end{array}$ & * & 3.92 \\
\hline $\begin{array}{l}\text { M. californicus } \\
\text { (Greenwald 1956) }\end{array}$ & $*$ & 7.2 \\
\hline $\begin{array}{l}\text { M. californicus } \\
\text { (Lidicker 1973) }\end{array}$ & * & 4.66 \\
\hline
\end{tabular}

No study of North American microtines has reported levels of postimplantation mortality as low as observed in this study (Table 6; 5.35\% of females with loss, $1.55 \%$ of embryos lost), although a current study of a coastal population of $M$. pennsylvanicus in Massachusetts (R. H. Tamarin, personal communication) shows a nearly identical level, $5.7 \%$ of litters with loss, and $1.9 \%$ of resorbing embryos. It is unclear what factors might be contributing to this mortality, for there is no observed relationship between density or season and the frequency of postimplantation loss. Pelikan (1970), studying Microtus arvalis in Czechoslovakia, examined $>1,000$ pregnant females and $>6,000 \mathrm{em}$ bryos and found $5.75 \%$ of females showing embryonic loss and $1.41 \%$ of embryos being resorbed. These figures are the same as the levels of postimplantation mortality in our study and that of Tamarin. The large sample permitted Pelikan to show that embryonic resorption was $2 \times$ as great in the period August through November compared to the spring-caught females, and that except for a high rate among the smallest (15to 19-g) females, mortality increased steadily with mass for all other females. Thus neither Pelikan's study nor ours supports the view that postimplantation losses should be greatest among low mass and reproductively inexperienced females.

In summary, estimates indicate that Kansas voles suffered slightly more preimplantation loss $(9.46 \% \mathrm{ver}$ sus $6.6 \%$ ) but much less postimplantation loss $(1.55 \%$ versus $7.0 \%$ ) compared to Indiana prairie voles, making the total prenatal mortality nearly equal in intensity, $11.0 \%$ of ova lost in Kansas and $13.6 \%$ in Indiana. Furthermore, there is no apparent association of prenatal mortality with density, which is consistent with the study of Keller and Krebs (1970).

\section{Ovulation rate}

We next examined ovulation rate to learn whether the pattern shown by embryo count is repeated. We predicted there would be a positive association between these 2 parameters since embryo number plus prenatal mortality equals number of corpora lutea ( $~=$ number of ovulations).

Because there is no significant correlation between copora count and body size for either parity class, primiparous and multiparous females are pooled and mean corpora counts are compared using the same method of lumping samples as with embryo counts. For 4-mo blocks and periods relating to density, the significant changes in mean embryo number also apply to corpora counts. Similarly, there are no differences between mean corpora counts for comparable bimonthly periods between years. For adjacent bimonthly periods, the 2 cases in which there is no correspondence in the level of significance of embryo and corpora counts are associated with the absence of prenatal mortality in the small bimonthly samples of parous females from May-June $1971(n=12)$ and JulyAugust $1972(n=4)$.

In summary, the pattern of low embryo number prior to the population peak is repeated for corpora count. Primiparous females tended to have a slightly higher ovulation rate during the winter prior to the peak and also during the peak itself (November 1971 to June 1972). Multiparous females tended to have a slightly higher ovulation rate during the population decline, and especially so in the second winter. Thus, although there was no statistically significant difference in the ovulation rates of the 2 parity classes, multiparous females had relatively greater ovulation rates at lower densities while the primiparous females produced substantially more ova in the winter of increasing density.

\section{Male reproduction during the cycle}

In this study only 30 of 364 males (8.2\%) with masses of $20 \mathrm{~g}$ or more lacked visible tubules in the cauda epididymides and are therefore considered to be nonfertile (Jameson 1950). Of these, 14 collected during the winter months of both years averaged $25.2 \mathrm{~g}, 3$ from May and June 1972 averaged $21.3 \mathrm{~g}$, and the remaining 13, taken during July and August of 1971, had a mean mass of $33.1 \mathrm{~g}$. The significantly higher average mass of the latter sample $(F=7.518, \mathrm{df}=3,26, P$ $<.001)$ suggests that testicular regression, the normal indicator of reproductive quiescence in the nonbreeding season of male cricetid rodents, occurred only once during the study. At other times, all males with masses $>30 \mathrm{~g}$ and the majority of $20-$ to $29-\mathrm{g}$ males were fertile. Because the slopes of the regression lines of fertile and nonfertile males are significantly different ( $F=10.069$, df $=1,360, .01>P>.005)$, the 2 classes are considered separately.

\section{Nonfertile males}

The analysis of nonfertile males is encumbered by the sampling methods used (omission of any male $<20$ 
TABLE 7. Linear regression analysis of paired testes mass (in milligrams) and body mass (in grams) in fertile $\delta \delta$. Four-mo periods and periods relating to density are used. $\mathrm{T}=$ test $\mathrm{H}_{0}, \beta=0, r=$ correlation between testes mass and body mass

\begin{tabular}{|c|c|c|c|c|c|c|c|c|c|c|}
\hline Sampling period & $N$ & $r$ & \multicolumn{2}{|c|}{$\begin{array}{l}\text { Paired testes mass } \\
\qquad \overline{(X} \pm \text { SD) }\end{array}$} & \multicolumn{2}{|c|}{$\begin{array}{l}\text { Body mass } \\
\overline{(\bar{X}} \pm \mathrm{SD})\end{array}$} & Slope & SE & $T$ & Intercept \\
\hline $\begin{array}{l}\text { May-Jun } 1971 \\
\text { Juł-Oct } 1971 \\
\text { Nov 1971-Feb } 1972 \\
\text { Mar-June } 1972 \\
\text { Jul-Oct } 1972 \\
\text { Nov 1972-Feb } 1973 \\
\text { Mar } 1973\end{array}$ & $\begin{array}{l}13 \\
78 \\
57 \\
46 \\
64 \\
61 \\
15\end{array}$ & $\begin{array}{l}.76 \\
.62 \\
.73 \\
.65 \\
.54 \\
.61 \\
.63\end{array}$ & \multicolumn{2}{|c|}{$\begin{array}{l}601.54 \pm 292.03 \\
693.72 \pm 384.13 \\
694.04 \pm 289.87 \\
882.17 \pm 276.49 \\
658.91 \pm 372.53 \\
546.89 \pm 270.88 \\
862.00 \pm 168.66\end{array}$} & \multicolumn{2}{|c|}{$\begin{array}{l}33.46 \pm 6.23 \\
41.05 \pm 7.63 \\
38.72 \pm 5.39 \\
37.96 \pm 6.64 \\
43.25 \pm 6.27 \\
37.00 \pm 5.25 \\
37.87 \pm 5.21\end{array}$} & $\begin{array}{l}35.36 \\
31.11 \\
39.18 \\
27.22 \\
32.22 \\
31.28 \\
20.39\end{array}$ & $\begin{array}{l}9.29 \\
4.54 \\
4.97 \\
4.75 \\
6.33 \\
5.35 \\
6.98\end{array}$ & $\begin{array}{l}3.81 * * \\
6.85 * * * \\
7.88 * * * \\
5.73 * * * \\
5.09 * * * \\
5.85 * * * \\
2.92^{*}\end{array}$ & $\begin{array}{r}-581.68 \\
-583.44 \\
-823.16 \\
-150.96 \\
-734.64 \\
-610.06 \\
89.78\end{array}$ \\
\hline \multicolumn{11}{|c|}{ Enects of density in fertile $\delta \delta$} \\
\hline $\begin{array}{l}\text { May } 1971-J a n 1972 \\
\text { prepeak period } \\
\text { Feb-Jun } 1972\end{array}$ & 127 & .64 & 668.74 & 352.34 & 39.36 & 7.30 & 30.99 & 3.31 & $9.36 * * *$ & -551.29 \\
\hline $\begin{array}{l}\text { peak period } \\
\text { Jul } 1972 \text {-Mar } 1973\end{array}$ & 67 & .60 & 852.84 & 271.28 & 38.67 & 6.27 & 26.03 & 4.29 & $6.07^{* * * *}$ & -153.79 \\
\hline postpeak period & 140 & .52 & 631.86 & 326.59 & 39.95 & 6.46 & 26.38 & 3.67 & $7.19^{* * *}$ & -422.14 \\
\hline
\end{tabular}

g), by the small sample (30) and by the absence of a linear relationship between body mass and testes mass for the nonfertile males examined $(r=.16)$. Keller and Krebs (1970) reported that a linear relationship held for male prairie voles having testes masses $<125 \mathrm{mg}$ and hence excluded all males with heavier testes weights from their analysis. This approach is not possible in our study because removal of males with testes masses $>125 \mathrm{mg}$ would eliminate all but 9 males from consideration. Overall, there were no seasonal or density effects for nonfertile males; testes masses tended to be uniform throughout the study, averaging $\approx 175$ $\mathrm{mg}$ for a nonfertile vole.

\section{Fertile males}

Using testes mass as an indicator of reproductive readiness, fertile males were examined in the same fashion as for pregnancy rate and embryo/corpora counts in an attempt to determine if the pattern of intervals of great and least reproduction applies to males also.

There is no significant difference in the regression coefficients of fertile males grouped by 4 -mo intervals ( $F=0.481$, df $=6,320$ ) or among periods relating to density $(F=0.593$, df $=2,328$ ) (Table 7 ). However, highly significant differences are detected (Table 8 ) for the adjusted means of 4-mo groups $(F=13.386, \mathrm{df}=$ $6,326, P<.001)$ and of density periods $(F=21.755$, df $=2,330, P<.001$ ). There is homogeneity among the slopes of regression lines and among adjusted means for the 34 -mo periods preceding and following the period of peak density. However, for pooled samples, the analysis of adjusted means indicates highly significant differences for comparisons between prepeak and peak populations $(F=28.344$, df $=1,191$, $P<.001$ ) and between peak and postpeak populations $(F=42.144$, df $=1,204, P<.001)$. Thus the populations preceding and following the period of peak den-

TABLE 8. Mean mass (in milligrams) of paired testes in fertile $\delta \delta$, grouped by 4-mo periods and periods relating to density. Adjusted estimates use the regressions of Table 7 to estimate the mean testes mass for a $40 \mathrm{~g} g$ of

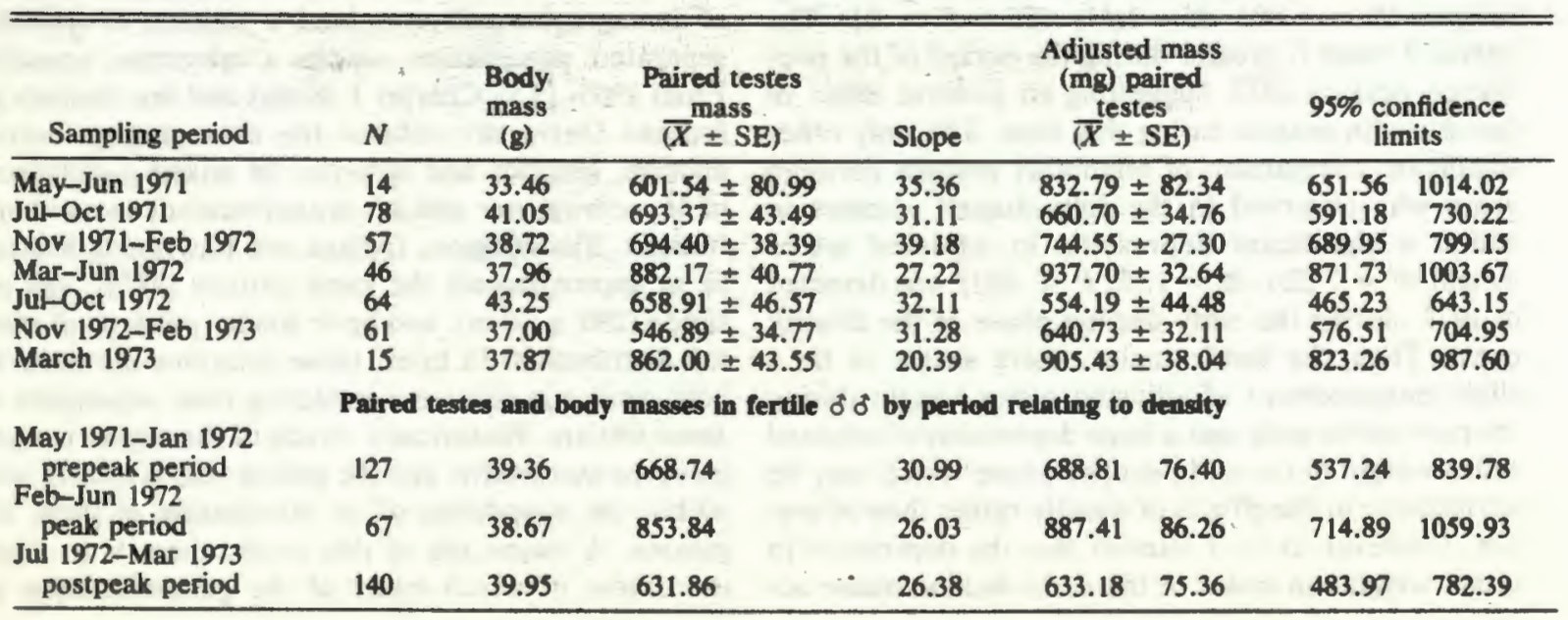




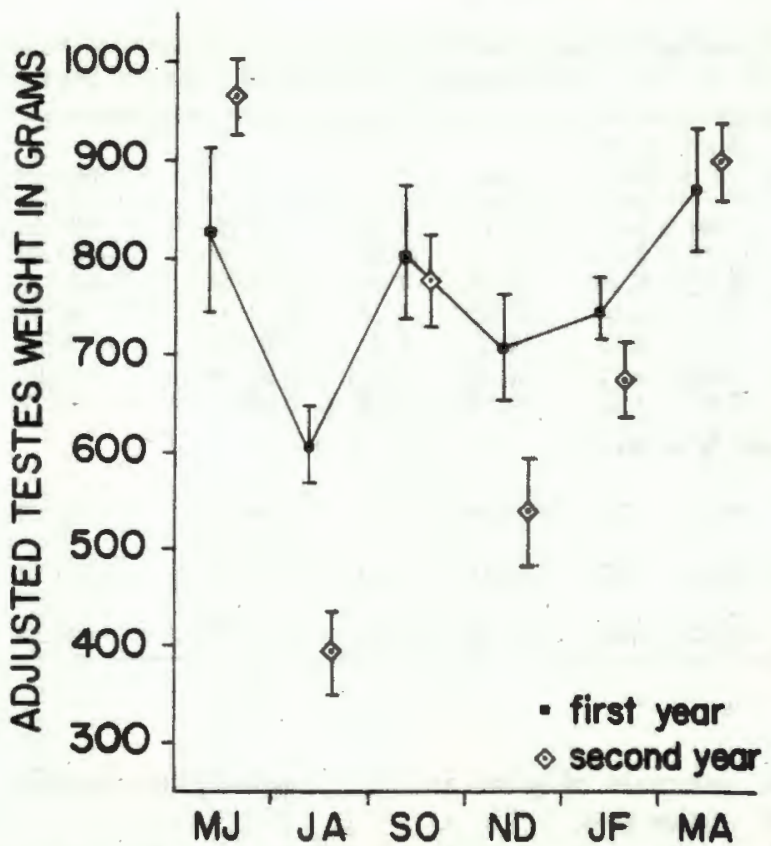

Fig. 7. Adjusted mean testes masses and standard errors for fertile $\delta \delta$ for bimonthly periods. First year and months as in Fig. 5.

sity had similar adjusted testes weights $(F=2.538$, df $=1,264$, NS) while the adjusted mean testes weight was significantly higher during the population peak (Table 8).

In an attempt to learn whether the increase in adjusted testes weight was attributable to the effects of peak numbers of voles or to seasonal effects alone, the fertile males were grouped by 2 -mo periods, and adjusted testes weights were then obtained using the regression data from Table 7. Comparisons of adjusted means were then made between adjacent 2 -mo periods and also between similar periods in different years (Fig. 7). Considering first the March-April and MayJune pairs, there is no difference in the slopes of regression lines between years, but among adjusted means there is a significant difference in the May-June samples $(F=6.803, \mathrm{df}=1,41, .025>P>.01)$. The adjusted mean is greater during the period of the population peak in 1972, suggesting an additive effect of density with season during this time. The only other significant comparison of bimonthly periods between years was observed in the July-August samples in which a significant depression in adjusted testes weight $(F=7.226$, df $=1,92, P<.001)$ was detected in 1972 , during the early decline phase of the density cycle. Thus, for fertile males, there seems to be a slight enhancement of adjusted testes weight during the population peak and a large depression of adjusted testes weight in the early decline phase which may be attributable to the effects of density rather than of season. However, it is of interest that the depression in testes weights in males of the early decline phase oc- curred in wetter than normal months. July, August, and September each exceeded normal rainfall amounts by $\approx 25 \%$. Although it is possible that these weather effects contributed to the reduction in testes weights, Fitch (1957) has suggested that rainfall, and the resultant burst of vegetative growth associated with it, may be the stimulus to resume breeding. Here we see the opposite effect, a diminution of adjusted testes weights at a time of increased rainfall. Overall, the pattern of rainfall in 1972 is unusual in that the first 6 mo (including the population peak) tended to receive considerably less and the latter 6 mo more than nor$\mathrm{mal}$ amounts.

The pattern shown by the adjusted testes weights of the bimonthly samples is one of great fluctuation, with an association of large testes weights with the reproductively active months of March, April, May, and October and reduced testes weights in the intervening periods of midsummer and midwinter. Significantly different adjusted testes weights were observed for $\mathbf{8}$ of the 11 comparisons between adjacent bimonthly samples; the exceptions were that no differences were detected between (1) the last 2 bimonthly periods of 1971, (2) the November-December 1971 and the January-February 1972 samples, and (3) March-April and May-June of 1972. The most extreme fluctuation is the $58 \%$ decrease in adjusted testes weight between the May-June sample of the late population peak and the early decline months of July and August of 1972.

In summary, nonfertile males showed no differences in testes weight throughout the cycle. Marked seasonal effects were observed among fertile males, with a strong association between high testes weight and high reproductive activity of the population. Finally, a trend in testes weight exists which suggests an enhancement during the population peak and a depression during the early period of declining numbers.

\section{Discussion}

The examination of changes in density and reproduction in $\boldsymbol{M}$. ochrogaster from eastern Kansas represents in many ways a first test of the repeatability of demographic and reproductive patterns of spatially separated populations within a microtine species. From 1965-1970, Charles J. Krebs and his students at Indiana University studied the demography, reproduction, genetics and behavior of mixed populations of $M$. ochrogaster and $M$. pennsylvanicus in southern Indiana. Bloomington, Indiana and Lawrence, Kansas lie at approximately the same latitude $\left(38^{\circ} \mathrm{N}\right)$ and altitude ( $290 \pm 30 \mathrm{~m}$ ), and have similar patterns of rainfall distribution. In brief, these locations are remarkably similar in climate considering their separation of some $800 \mathrm{~km}$. Historically, much of the region in each instance was prairie, and the prairie vole is clearly well within the boundaries of its distribution at these locations. A major aim of this study, then, is to learn the extent to which many of the generalizations of 
demography and reproduction attributed to all microtines will apply even to the same species in different localities. At present, many investigators take the approach, elaborated by Krebs et al. (1973), that a single mechanism underlies all microtine cycles; consequently, the response shown by subarctic woodland microtines should be similar to that of midtemperate grassland microtines, because all are "marching to the same drummer." There seems to be some justification for making this assumption because, in many instances, the population attributes are remarkably similar (see Krebs and Myers 1974 for review). Here we show the patterns within a species and leave it to the reader to determine the relative perils of extrapolating these patterns or principles to other species or genera.

We consider the 6 attributes discussed by Keller and Krebs (1970): (1) winter breeding precedes the cyclic. increase, (2) breeding ceases early in the year of cyclic peak and is initiated late the following spring, (3) early maturation precedes the cyclic increase, (4) litter size is independent of cyclic periods, (5) prenatal mortality is not related to cyclic periods, and (6) high body weight is associated with the cyclic peak. These attributes overlap and cannot be discussed individually without much repetition resulting. Therefore, they will be discussed in relation to density, mechanisms of increasing reproductive output, and finally as they relate to a model of population regulation as proposed by Schaffer and Tamarin (1973).

\section{Density}

Microtine cycles vary from 2 to 5 yr in duration, with many having 3- to 4-yr intervals between peaks. The amplitude of the cycle, or relative level of change, seems to vary among species, with some, such as Clethrionomys rufocanus, a subarctic woodland vole, increasing to only 3 to $4 x$ the minimal densities (Kalela 1957 ) whereas others, such as $\boldsymbol{M}$. oregoni, have been reported to increase $100 \times$ or more (Fed. Coop. Ext. Ser. 1959). The prairie vole seems to have an intermediate level of change, dependent partly on the method of estimation of numbers, fuctuating between 6 per hectare (Fitch 1957, p. 140) to $\approx 358 /$ ha (Martin 1956, p. 379). In fact, the estimates made using the minimum number known to be alive on demographic grids, show that both in Indiana (Krebs et al. 1969) and in Kansas (Gaines and Rose 1976) numbers fluctuated between $\approx 15$ and $173 /$ ha .

Concerning density, 2 principal differences are observed between the Indiana studies and those (including Martin 1956 and Fitch 1957) in eastern Kansas. The 2 cycles in Indiana were characterized by rapid winter declines following a protracted period of peak density, whereas the populations of Kansas prairie voles tend to decline gradually, beginning in the months of May and June, and some at least have peak densities for very short periods, probably on the order of 4 wks compared to $\approx 1 \mathrm{yr}$ in Indiana. In our study, the period of peak density has been defined in most instances to include the 2 mo preceding and following the month of greatest density, April 1972. This grouping permits a meaningfully large sample size and yet is not so broad as to overlap into increase and decline phases too severely. Selection of a 3-mo period of peak density does not change any results.

In the Indiana studies, as well as. in ours, changes in the level of natality do not explain either the increase or the decline in numbers. We observed a generally high production of young throughout the study. Although litter size increased significantly during the months of the population peak $\overline{(X}=3.69$, compared to the prepeak litter size of 3.04 ), there was no observed decrease in either litter size or pregnancy rate which might explain the population decline. Neither have changes in the length of the breeding season contributed to the decline, for pregnancy rates were uniformly high except for 3 brief seasonal nonbreeding periods of $\approx 1$ mo each. However, in Indiana, the winter decline is associated with a decrease in breeding during this season. Thus, a combination of reduced litter production and winter mortality may have contributed to the rapid decline of both of the Indiana crashes. Since the declines (including Fitch 1957 ) seem to occur in Kansas during the summer months, at a time when food shortages and vagaries of the weather have less effect on mortality as compared to the midwinter season, the crash is not so precipitous. In Indiana, desity-related mortality factors appear to have acted in company with the climatic factors; in Kansas, these effects are separated.

\section{Length of breeding season}

Many studies of microtine rodents have reported that changes in the intensity of breeding are associated with the density cycle (Krebs et al. 1969; Sadleir 1969, Ch. 5, Keller and Krebs 1970). However, none since Hamilton (1941) has claimed that changes in natality may contribute to the causes of cyclic change, nor has anyone given a satisfactory explanation of what factors might alter the length of the breeding season or initiate its resumption. Weather variables have most often been examined as possible factors influencing the level of breeding. For example, Martin (1956) attributed the midsummer decline in numbers to flooding in one year and drought in another. Fitch (1957) observed that resumption of breeding was roughly correlated with rainfall following periods of relative drought, and an even better correlation existed if a 1mo lag time was considered. This suggested to him that rainfall was indirectly important as the stimulus to resumption of breeding, with the burst of new, green vegetation supplying factors vital to higher breeding levels. Although the importance of rainfall and of new, green vegetation over extended time periods can hardly be denied (see Greenwald 1956, Hoffmann 1958, Lidicker 1973, on the timing of breeding 
in $M$. californicus, 3 bits of evidence from this study indicate to us that rainfall is not of overriding importance in eastern Kansas populations of the prairie vole.

Low pregnancy rates were observed in the month of July in both years, yet July is the fourth wettest month on the average and is preceded by the wettest $2 \mathrm{mo}$. In the years of this study, July rainfall exceeded normal amounts by $\approx 84$ and $32 \mathrm{~mm}$; June amounts were somewhat below normal (Rose 1974). Thus, we observed a reduction in pregnancy rate at the time a supposedly favorable stimulus was received. Secondly, the year of peak density, 1972, was climatically atypical with 6 generally drier than normal mo preceding 6 exclusively wetter mo. Of particular interest is the observed cessation of breeding activity in July and August of 1972, 2 wetter than normal mo following a relatively long period of drier than normal weather. If breeding intensity is closely related to rainfall amounts, breeding activity should resume or intensify. This did not happen in midsummer 1972. Finally, in March 1973, precipitation exceeded normal amounts by $4 x$ at the Lawrence weather station and perhaps $6 x$ in the main study area, yet pregnancy rates were comparable to the previous March, and to the months of March in the studies of Jameson (1947), Martin (1956), and Fitch (1957), all done in the same general area. In this instance, excessive rainfall did not reduce pregnancy rates, which is not to deny that local flooding may have greatly affected mortality rates among young in the nest.

Generally, then, rainfall data are inconclusive indicators as predictors of breeding intensity in this population. Differences in local topography and soil composition buffer or accentuate the effects of rainfall to a large degree. For example, Quarry Field, the study site of Martin (1956) (our Grid A, Gaines and Rose 1976), is a shallow-soiled, flat hillcrest and is highly susceptible to both puddling and desiccation. Site 1 is a south-facing slope with sandy soil, but terraced. Here, during extended periods of drought, certain areas might become inhospitable compared to the terraces. Hill Field (Grid B) is a well-drained, north-facing slope with deep, loamy soils; direct sunlight does not strike the ground during some seasons, and evaporation rates must be low compared to the nearby site 1 . These nearly contiguous study areas probably receive identical rainfall from year to year, yet Hill Field is likely to have a much more stable environment in terms of a continuous source of moisture available to perennial grasses, the major vegetational component of these study areas. Thus, equal amounts of rainfall might fall on 2 adjacent study areas, but the effect on the environment can be very different, depending on the slope, angle of exposure, and soil factors.

The possibility that breeding intensity in a microtine species is actually regulated by rainfall is testable, requiring only a large tract of land, uniform in vegeta- tion, soil, drainage, and exposure, plus the potential to irrigate certain plots and not others. Until such wellreplicated studies are undertaken, it will continue to be impossible to state with authority that breeding activity is related to rainfall.

An equally perplexing problem relates to the factors which influence the level of winter breeding. Winter breeding in $\boldsymbol{M}$. pennsylvanicus was positively associated with the presence of an insulative snow cover in Minnesota (Beer and MacLeod 1961), but in eastern Kansas (and in southern Indiana as well) snow rarely remains on the ground for as long as $\mathbf{2} \mathbf{w k}$. It is difficult to imagine how prairie voles at these locations could attune breeding to such an unpredictable and shortlived stimulus. In neither our study, where winter breeding occurred during the decline, nor that of Keller and Krebs (1970), where it did not, was there an indication of 1 or more extrinsic factors which might cause or permit winter breeding to occur. Except for the somewhat colder November and December of 1972, no strong deviation from normal occurred with respect to rainfall, snowfall, or temperature, and the conditions were very similar between years in the wintertime. Snowfall amounts were $\approx 50.8 \mathrm{~cm}$ in each year, and brief warming trends appeared to result in the growth of some vegetation during each winter month. One possible important difference between the Kansas and Indiana study areas is that Bromus inermis is the dominant vegetation in Kansas, and Festuca sp. is dominant in Indiana. The studies of Pinter and Negus (1965) and Negus and Pinter (1966) indicate that the presence of green vegetation and the steroids available in this vegetation might be important in determining the level of reproductive activity in a population. The possibility that qualitative differences in the nutrition of cultivated brome and fescue might be contributing to the intensity of winter breeding is testable.

Winter breeding of prairie voles has been reported in Indiana (Corthrum 1967, Keller and Krebs 1970), Ohio (DeCoursey 1957), Missouri (Fisher 1945), and eastern Kansas (Jameson 1947, Martin 1956, Fitch 1957). Only Keller and Krebs (1970) related winter breeding to density changes in the population. They reported substantial breeding only in the winter of cyclic increase, with a reduced level of breeding the following November and December, and none in January and February. Based on the proportion of females in late pregnancy, Fitch (1957) reported no breeding among prairie voles during December and January of the year prior to the 1951 population peak in eastern Kansas. In fact, the absence of breeding was a characteristic feature of most of the months from December through February in his study of nearly 4-yr duration. In our study, both the high pregnancy rate and embryo number of the fall season of 1971 were sustained throughout the entire winter, there being no significant reduction in reproductive output 
during any month. In the winter following the peak, there was a $40 \%$ reduction in the pregnancy rate compared to the first winter, due mainly to a sharp drop during December. There was no change in embryo production per female at this time. Thus total production of young was likewise reduced $\approx 40 \%$ compared to the winter preceding the population peak. Males show a slight but nonsignificant reduction in testes weight during the second winter as well, but in all instances any male with a mass of $30 \mathrm{~g}$ or more was fertile. Overall, a relatively high level of breeding, representing $55 \%$ of the maximum observable pregnancy rate, was observed in the second winter. Such a high level of winter breeding is clearly not the random or infrequent type of breeding of a few individuals (formerly reported as anecdotes in the literature), but represents systematic breeding by a large portion of the population.

Keller and Krebs (1970), borrowing the idea of Chitty (1955), suggest that if qualitatively different types occur (some able to breed in winter, others not), then the few individuals they observed to breed in November and December (but not in January or February) of the population decline in Indiana may represent those superior survivors of the period of peak density. This possibility is not supported by the findings of our study, where 12 primiparous pregnant females trapped from November 1972 through February 1973 averaged only $33.13 \mathrm{~g}$ in mass and a short $109.00 \mathrm{~mm}$ in body length. Based on observed growth rates on the demographic grids (Gaines and Rose 1976), these females must have been born in September or October, and therefore cannot be survivors of the period of sharp population decline. The multiparous females taken during this same period may have survived the population crash the preceding June, but they are no heavier or longer than multiparous females of the previous winter, possibly indicating a similar mix of sizes during both years.

The observation that small, primiparous females constitute the majority of the breeding population in both winters differs from the findings of Keller and Krebs (1970) and Jameson (1947). These investigators noted that late fall or winter breeding was limited to heavier females. Jameson (1947) observed that in the autumn, $85 \%$ of pregnant females were large, mature individuals, most of which disappeared in November, resulting in a scarcity of adult females through the winter. He explained the absence of pregnant voles in December and January by the relative absence of mature females. Keller and Krebs (1970) found only heavier females breeding during the winter of cyclic increase, and also noted that only the heavier males were fertile at this time. In our study, from November 1971 through February 1972, 22 of 33 pregnant females were primiparous, lightweight individuals (Table 4). The next year, 12 of 21 females, primiparous and with low average weight, were pregnant during these colder months. Clearly, breeding is not invariably limited to heaver, older, and presumably reproductively experienced females during the months of late autumn and winter.

\section{The reproductive cycle}

Three concordant lines of evidence, each independently derived, seem to indicate that the prairie vole in eastern Kansas at least, and possibly elsewhere, has adjusted its breeding schedule to accommodate both the harsh desiccating conditions of midsummer which this species still encounters over the western third of its present distribution and the severe midwinter conditions routinely faced by all populations except those in the southernmost tier of states. Pregnancy rate, litter size, and adjusted testes weight all show a trend toward breeding peaks in March-April and September-October, and breeding depression in midsummer and midwinter. In July 1971, July and August of 1972 , and December 1972 , only 10 of 61 parous females were pregnant, making an average pregnancy rate of $16.4 \%$ for these midsummer and midwinter months of depressed breeding activity; December 1971 had a pregnancy rate of $40 \%$, and all remaining months had higher rates. Keller and Krebs' (1970) data do not permit an examination of the tendency toward a "July depression" in breeding, but Jameson (1947) reported a sharp decline from June into July and August; Martin (1956) noted a midsummer dip, especially in 1952 (Fitch's decline); Fitch (1957) reported that, except in 1950, July females had the lowest pregnancy rates among nonwinter months. Corthrum (1967) indicated a similar decline in July populations in Indiana during $1 \mathrm{yr}$. These studies, including 3 from our general study area (Jameson 1947, Martin 1956, and Fitch 1957) lend support to the reality of the July reproductive depression which we observed during both years of this study. Based on observation of nipple size, similar July depressions were noted on most of the demographic grids in 1971, 1972, and 1973 (Gaines and Rose 1976) and were also observed in 1970 on site 10 (R.K.R., personal observation). Pregnancy rates, then, are lowest in December-January and in the July depression, and highest in March-April and September-October.

Examination of Fig. 6 reveals that litter size is also sharply reduced in midsummer. We have already demonstrated that these changes in embryo count cannot be due to size changes among individuals of the population of July females, because overall, there is no correlation of body mass (or body length) and corpora or embryo count. In fact, July females have very high average body masses, and if there were a significant correlation between body mass and embryo count, embryo counts adjusted to a $40-\mathrm{g}$ female vole would be rendered even lower. The bimontly periods including July and August show substantially and in some cases significantly smaller litters compared to females 
from adjacent bimonthly periods (Fig. 6). Reduction in midwinter litter size is not so pronounced. Peak embryo production was observed in the bimonthly samples including March (also noted by Jameson 1947, Fitch 1957) and was only slightly reduced in September-October by comparison.

Changes in adjusted testes weight parallel embryo production remarkably well. In 9 of 11 comparisons of bimonthly samples (Figs. 6 and 7), change in embryo count and adjusted testes weight are in the same direction. Exceptions are within the population peak, when adjusted testes weight increased into May-June, while embryo count decreased sharply during this interval, and in January-February 1973, when adjusted testes weight increased at a time when embryo count decreased $<0.1$ per female. Thus adjusted testes weight was a poor indicator of change in embryo number only once, during the population peak, when adjusted testes weight increased at a time of substantial reduction in embryo production. Removal of the single May-June sample and application of the Spearman rank correlation (nonparametric) test (Siegel 1956, p. 202) results in a significant correlation between change in embryo count and adjusted testes weight $\left(r_{n}=.75\right.$, $t=3.21, .02>P>.01$ ). Most studies (except DeCoursey 1957) attribute to females the depression or resumption of breeding intensity, with males usually showing a substantial lag time. Here we observe a high degree of correspondence between the changes in adjusted testes weight and changes in embryo count, with a lag apparent only in the overshoot of the males in May-June of the population peak.

Change in pregnancy rate (Fig. 5) is also positively related to the changes in litter size and adjusted testes weight, especially so during the periods of reduced breeding intensity. Application of Kendall's coeffcient of concordance (W) (Siegel 1956, p. 229) results in a significant concordance among these 3 reproductive parameters $\left(W=.854, \chi^{2}=25.62,10 \mathrm{df}, .01\right.$ $>P>.001)$. This observation means that for this study, there was a strong tendency for pregnancy rate, litter size, and adjusted testes weight to vary together, i.e., to adjust the level of intensity of breeding in unison. The strong concordance among these 3 parameters suggests to us that Kansas voles are responding to similar stimuli, whether intrinsic or extrinsic.

\section{Acceleration of breeding rate}

There are 4 possible ways to accelerate the breeding rate in an iteroparous species: (1) reduce the interval between litters, (2) increase the pregnancy rate, (3) decrease the time to sexual maturity, and (4) alter the sex ratio in favor of females. Keller and Krebs (1970) have outlined the biases in the determination of the interval between litters, namely, that lactation is difficult to assess, that pregnancy is not detectable until about day 6, and that in Microtus, induced ovulation may be the rule. Therefore, they considered the first 2 methods together.

With the work of Richmond and Conaway (1969) it is now clear that in $M$. ochrogaster, ovulation is induced and follows copulation by $\approx 10 \mathrm{~h}$. A postpartum estrous occurs at about the time of parturition, which is sustained for as long as 6 days in the absence of mating. Among lactating females, Richmond (1967) observed intervals of 19 to 23 days in $61 \%$ of 431 cases, with only $1.4 \%$ of litter intervals being as short as 19 or 20 days. No lactation delay in implantation is apparent in this species. In fact, postpartum matings occurred in the majority of instances, resulting in a major peak in litter intervals at $\approx 21$ days. A smaller peak occurred between 34 and 43 days in females which failed to conceive immediately after parturition, suggesting some sort of anestrous associated with midlactation. Richmond observed that a typical estrous cycle does not occur in this species, and using several treatments, observed proximity to males to be the strongest stimulus to induction of estrous.

In Richmond's study, $39 \%$ of females did not have postpartum matings in the reproductively optimal conditions of a laboratory cage containing a parturient female and a male. It would not be surprising to find postpartum matings in nature at a lower frequency of parturitions, thereby tending to increase the interval between litters and consequently reducing the pregnancy rate somewhat.

We have found pregnancy rate (the proportion of females visibly pregnant compared to the number of potentially reproductive females, whether defined by weight or parity critieria) to be remarkably high throughout the density cycle except for the 3 brief periods discussed in the previous section. With a gestation period of 21 days, the observable pregnancy rate in this species is .71 , because embryos cannot be detected for $\approx 6$ days (Hoffmann 1958). The 431 females in the study of Richmond (1967, p. 32) had an average litter interval of 26.6 days, for an observable pregnancy rate at any instant of .565 . This value is virtually identical to the observed pregnancy rate for our entire study, .560 . This suggests to us that: (1) overall, the populations of prairie voles we have monitored in nature are approaching maximal iteroparity, for no decrease in litter interval was observed compared to the laboratory colony (Richmond 1967) where males were readily available to insure postpartum breeding, (2) male fecundity cannot be regulating litter interval in any real way ( $92 \%$ of males were observed to be fertile in our study), and (3) the distribution of postpartum matings in our study may closely approximate that observed by Richmond, resulting in postpartum matings in the majority of females in our study.

The potential for population increase is greatly enhanced if development time is shortened even slightly (Cole 1954, Lewontin 1965). Since the determination of exact age is difficult to make in wild-caught voles, 
early age is necessarily equated with smaller size in this species.

With respect to the relationship between body mass and maturity, several interesting comparisons of our study with that of Indiana populations of $M$. ochrogaster studied by Keller and Krebs (1970, p. 271) are that:

1) the sexes mature at about the. same weight each season, although Kansas voles do so at masses $4 \mathrm{~g}$ less than Indiana prairie voles;

2) median weight at sexual maturity in nonpeak populations is lowest in the spring and increases linearly throughout the year in both Kansas and Indiana;

3) at high densities in Indiana the median weight at sexual maturity was unchanged for females and slightly increased for males, compared to predictions based on the season of occurrence. In our study, the opposite effect is indicated for females, namely, an apparent depression in weight at sexual maturity of peak populations. Males showed slight differences during this time;

4) there was a 4 to $5 \mathrm{~g}$ reduction in the median mass at sexual maturity of females, but not of males, in the spring following the population peak in Indiana. Such a shift may already have occurred during the peak density phase in the Kansas populations.

The Kansas data support the hypothesis that a decrease in age at sexual maturity may contribute in some measure to the attainment of peak densities. The study of Keller and Krebs (1970) does not, but is in agreement with Mayr's (1963, p. 200) view that the reduction in age at sexual maturity occurs during the recovery period, i.e., in the phase of declining or low numbers.

For Kansas voles, it is unclear whether the reduction in weight at sexual maturity of females during the population peak is related to the cause of the peak density or is an effect of high population number. Other studies of microtine reproduction have observed an inverse relationship between density and maturity (Clarke 1956, in an experimental population of Microtus agrestis; Greenwald 1957, in $M$. californicus; Stein 1957 , in $M$. arvalis), although Hoffmann (1958) reported no change in age at maturity in $M$. californicus and $M$. montanus. Keller and Krebs (1970) noted a trend toward earlier maturation only in the period of cyclic increase. The timing of attainment of peak density with respect to the growing season may be quite important in determining the levels of difference observed in these studies. In our case it is possible, perhaps even likely, that the depression in median weight at sexual maturity among peak females, and to a lesser extent among males, results from a synergistic tendency of spring-born voles to mature at earlier ages coupled with the density effects seen by Clarke (1956), Greenwald (1957), and Stein (1957).

Whatever effect the reduction in age at first breeding might have had on altering the potential for population increase, it is clear that it was short lived, because the population was not maintaining peak numbers in May and June, defined as the last 2 mo of the population peak. The period of peak density was brief, and the acceleration of the breeding rate due to a reduction in age at first mating must have been very slight. Therefore, it is unlikely that this parameter resulted in the attainment of peak density, although the observed amplitude might have been slightly lowered had not the few young females contributed a litter or at most 2 before the population declined sharply in numbers (Fig. 1).

In our study, a slight excess of females was observed among the voles with masses $20 \mathrm{~g}$ or more taken by live trapping. During the 5 mo of the population peak, this same trend was noted, with females outnumbering males ( 78 to $71, \chi^{2}=0.33,1 \mathrm{df}, \mathrm{NS}$ ). Thus, there appears to be no alteration of sex ratios favoring females to a greater extent during the period of greatest densities. Myers and Krebs (1971) have considered the demographic implications of distorted sex ratios and presented evidence that in 1 instance (Fig. 1, p. 327), females of $M_{\text {; pennsylvanicus were }}$ more common during the period of peak density and less common during the months of population decline. They pointed out that in 5 populations of $M$. pennsylvanicus and 7 populations of $M$. ochrogaster, the sex ratios of newly caught voles showed an excess of males for both species ( 54 and $56 \%$ ) compared to a deficiency of males in both species ( 45 and $47 \%$ ) when all resident animals are considered. After examination of the factors contributing to this observed shift from male to female predominance, Myers and Krebs concluded that the population sex ratio seems to be $1: 1$, as predicted by the hypothesis of Fisher (1958). We find no reason to disagree.

\section{A model of population regulation}

A model by Schaffer and Tamarin (1973) predicted that reproductive effort $(E)$ should change with population density $(N)$ if voles respond to density by maximizing their Darwinian fitness. They assume that if one of the effects of density is to decrease the viability of prereproductives, the optimal reproductive effort of a vole will decline as density increases. Further, if voles adjust their reproductive effort toward the optimal effort, and allowing for a lag at least as long as the gestation period, reproductive effort and density, when displaced from equilibrium, will show an inverse relationship. Essentially, this model predicts that litter size and other components of reproductive effort will be reduced at high density and adjusted upward during periods of lower density. Our results are not in agree- 
ment with this prediction, and other observations violate several of the assumptions of this model.

For example, we find no age-specific changes in reproductive effort (Schaffer and Tamarin 1973, p. 111, 118 ) in our study, for there is no significant regression of corpora count on body mass, and no difference in either the number of corpora or of embryos produced by primiparous and multiparous females. In fact, only during the 4-mo period from March to June, 1972 (in the population peak), when the median age at sexual maturity of females was depressed 4 to $5 \mathrm{~g}$ compared to the preceding spring, was there a significant reduction in embryo count among primiparous females. In some of the 4 mo periods, primiparous females had, on the average, larger litters than multiparous females, and overall litter sizes were nearly identical.

Nor do we find any evidence that mortality increases during times of increased breeding (Schaffer and Tamarin 1973, p. 115). We have no direct evidence relating to mortality because of the nature of the sampling procedures, but we did not observe periods of increased breeding per se, for levels of breeding, defined by pregnancy rate, are uniformly high throughout the study, except for the brief periods of cessation of breeding in both midsummers and in midwinter following the period of peak density. We do not dispute the fact that mortality was high during and especially following the time of peak density, for this seems to be the only plausible explanation for the population decline. This presumed increased mortality cannot, however, be related to increased breeding during this time, but must be related to some effect of density itself.

Schaffer and Tamarin (1973, p. 119) further suggest that during periods of reduced breeding, younger voles curtail their breeding activities to a greater extent than do older voles. Direct and indirect evidence from our study does not support this contention. For example, during August 1972, both subadult $(20-29 \mathrm{~g})$ individuals from the sample were pregnant, compared to only 1 of 13 among the adults $(30+\mathrm{g})$. Similarly, in December of 1972, 2 of 5 parous subadults were pregnant, but none of 13 adult females were. Indirect evidence comes from the 4 mo samples from November to February of both years, in which $\approx 60 \%$ of the pregnant females were primiparous.

Schaffer and Tamarin (1973, p. 119) state that if voles adjust their reproductive effort to keep them close to $\hat{E}(N)$ (the maximum reproductive effort for a given density), an equilibrium will result. Thus, at high density, optimal reproductive effort should result in litters of reduced size, and this will tend to return the population to the equilibrium density. In the population we studied, we did not observe $\hat{E}(\mathrm{~N})$ to change in the predicted direction during any of the 3 periods relating to high density. Mean litter size, a major component in $\hat{\mathrm{E}}(\mathrm{N})$, for these periods is $3.04,3.69$, and 3.70 respectively. The prediction that litter size will be greater before the peak, reduced during the peak, and increased during the period of declining numbers is partially fulfilled only during the decline, when litter sizes remained high.

Finally, relating to the time lag built into Eq. 8 (Schaffer and Tamarin 1973, p. 120), we have presented evidence here that both males and females tend to adjust their reproductive rates together, if not instantly, at least in unison, and often for very brief periods only. This adjustment is not through prenatal mortality in females but instead by an alteration of the number of ova released and of females pregnant, as well as by changes in the adjusted testes weights of males. The reduced time lag that results will tend to diminish the oscillatory component and will change the shape of Fig. 10 (Schaffer and Tamarin, p. 119) somewhat. The important effect we have noted, however, is that stability cannot be achieved in our populations as Schaffer and Tamarin perceive it, because in our populations, $\hat{\mathrm{E}}(\mathrm{N})$ increased significantly during the period of peak density. The reproductive effort of Kansas prairie voles seems to be less related to density than to season, and overall is better described as maximal, not optimal.

\section{Conclusions}

Populations of $M$. ochrogaster in eastern Kansas repeat a number of patterns of reproduction observed elsewhere. These include: (1) the tendency of voles to mature at lower weights early in the breeding season and for median weight at sexual maturity to increase throughout the year, (2) density-indepedent prenatal mortality, (3) (slightly) increased body length, if not body mass; among voles of the population peak, (4) 1:1 sex ratios throughout the cycle, (5) the apparent failure of weather patterns to explain changes in reproductive levels, (6) midsummer depression in breeding activity in prairie voles, and ( 7 ) the failure of natality to explain the changes in density.

However, we have observed a deviation from "normal" with respect to many of the attributes of cyclic populations of microtine rodents (Krebs and Myers 1974). We have observed no breeding season per se, but only brief periods of reproductive inactivity associated with midsummer and in midwinter to a lesser extent. Consequently, reduced levels of winter breeding prior to the population peak, little or no winter breeding in the population decline, shortening of the breeding season in the summer following peak densities, and acceleration of the breeding rate prior to the attainment of peak density are all absent here. We find no tendency for the population to adjust litter size downward during the period of peak density or in the wintertime. We also find no tendency for heavy individuals to be associated with the population peak, or to constitute the majority of breeding females during the winter months. Litter size increased significantly in the period of peak numbers and may have contributed in some measure to the determination of realized 
amplitude. However, litter size remained high during the population decline, and density changes cannot be explained on this basis. Changes in juvenile and adult mortality, which were not examined here, must be invoked to account for the reduction in density.

At least part of the explanation for these variances may relate to the evolutionary history of this species. The patterns of reproduction we report here may represent a composite of the patterns shown by the coldadapted microtines, such as $M$. pennsylvanicus, and the dry-adapted species, $M$. californicus. Throughout part of the range of the species, including eastern Kansas, periods of intense winter weather rarely exceed 2 wk. Although eastern Kansas does not regularly experience summer drought, from central Kansas to the foothills of the Rocky Mountains average rainfall is $254-381 \mathrm{~mm}$ and midsummer desiccation is both predictable and considerable. The stresses of desiccation are more formidable to a short-eared, short-tailed rodent than are those of cold, and there is an indication that throughout its present distribution the prairie vole still depresses its reproductive output in midsummer, a probable reflection of its origin in the Central Plains. Microtus californicus has adjusted its breeding schedule to avoid bringing forth litters in the midsummer drought; most other microtines have to confront winter as the major obstacle to successful breeding. But the prairie vole, in the evolutionary sense, has had to compensate for both harsh seasons. Based on the observations of this study, the prairie vole seems to have adjusted to both stresses by breeding more or less continuously, with the midsummer depression possibly reflecting the evolutionary history of the species and the winter depression relating to a complex of factors including weather, density, and quality of the habitat.

\section{ACKNOWLEDGMENTS}

This paper is a portion of a dissertation submitted to the Graduate School of the University of Kansas by the senior author, in partial fulfillment of the requirements for the Ph.D. degree in Biology. We are grateful to the University of Kansas Endowment Association for providing field facilities and to Messrs. Howard Kampschroeder and Gaylord M. Schneck for consenting to the use of their land. Ann Schlager made Figs. 1 through 4, and Verner Plott prepared Figs. 5 through 7. Robert S. Hoffimann and Norman A. Slade, also of the Department of Systematics and Ecology, Jan O. Murie and an anonymous reviewer contributed several useful suggestions to earlier versions of this paper. Financial assistance was provided by an NSF traineeship in Systematic and Evolutionary Biology, a grant to M. S. G. (NSF GB 29135), General Research Grant 3822-5038 of the University of Kansas, and the Kansas Biological Survey. We also thank Charles J. Krebs of the University of British Columbia for computer programs and the University of Kansas Computation Center for the use of their facilities. Finally, R.K.R. thanks his wife, Aleene, for her continued support during this (and other) ecological studies.

\section{Literature Cited}

Beer, J. R., and C. F. Macleod. 1961. Seasonal reproduction in the meadow vole. J. Mammal. 42:483-489.
Bliss, D. I. 1967. Statistics in biology, Vol. 1. McGraw-Hill, New York. 558 p.

Brambell, F. W. R. 1948. Prenatal mortality in mammals. Biol. Rev. 23:370-407.

Chitty, D. 1955. Adverse effects of population density upon the viability of later generations, p. $57-67$. In J. B. Cragg and N. W. Pirie [eds.], The number of man and animals. Oliver and Boyd, London.

Chitty, H., and D. Chitty. 1962. Body weight in relation to population phase in Microtus agrestis, p. 77-86. In J. Kratochivl and J. Pelikan [eds.], Symp. Theriologicym, Brno, 1960. Czechoslovak Acad. Sci., Praque.

Clarke, J. 1956. Influence of numbers on reproduction and survival in two experimental vole populations. Proc. $\mathbf{R}$. Soc. London, Ser. B. 144:68-85.

Clough, G. C. 1968. Social behavior and ecology of Norwegian lemmings during a population peak and crash. Pap. Norwegian State Game Res. Inst., Ser. 2, No. 28.50 p.

Cockrum, E. L. 1948. The distribution of the hispid cotton rat in Kansas. Trans. Kansas Acad. Sci. 51:306-312.

Cole, L. C. 1954. The population consequences of life history phenomena: Q. Rev. Biol. 29:103-137.

Corthrum, K. W., Jr. 1967. Reproduction and duration of placental scars in the prairie vole and the eastern vole. J. Mammal. 48:287-292.

DeCoursey, G. E., Jr. 1957. Identification, ecology and reproduction of Microtus in Ohio. J. Mammal. 38:44-52.

Elton, C. 1942. Voles, mice and lemmings, problems in population dynamics. The Clarendon Press, Oxford. $496 \mathrm{p}$.

Federal Cooperative Extension Service. 1959. The Oregon meadow mouse irruption of 1957-58. Oregon State College, Corvallis. $88 \mathrm{p}$.

Fisher, H. J. 1945. Notes on voles in central Missouri. J. Mammal. 26:435-437.

Fisher, R. A. 1958. The genetical theory of natural selection. 2d revised ed. Dover, New York. 291 p. (Originally published in 1930).

Fitch, H. S. 1950. A new style live trap for small mammals. J. Mammal. 31:364-365.

- 1957. Aspects of reproduction and development in the prairie vole (Microtus ochrogaster). Univ. Kansas Mus. Nat. Hist. Publ. 10:129-161.

Fleharty, E. D., and L. E. Olson. 1969. Summer food habits of Microtus ochrogaster and Sigmodon hispidus. J. Mammal. 50:475-486.

Gaines, M. S., and C. J. Krebs. 1971. Genetic changes in fluctuating vole populations. Evolution 25:702-723.

, and R. K. Rose. 1976. The population dynamics of Microtus ochrogaster in eastern Kansas. Ecology 57:11451161.

Greenwald, G. S. 1956. The reproductive cycle in the field mouse Microtus californicus. J. Mammal. 37:213-222.

1957. Reproduction in a coastal California population of the field mouse, Microtus californicus. Univ. California Publ. Zool. 54:421-446.

Hamilton, W. J.. Jr. 1941. Reproduction of the field mouse Microtus pennsylvanicus (Ord.). Cornell Univ. Agric. Exp. Stn. Mem. 237. 23 p.

Hoffmann, R. S. 1958. The role of reproduction and mortality in population fluctuations of voles (Microtus). Ecol. Monogr. 28:79-109.

Hoffmeister, D. F., and L. L. Getz. 1968. Growth and ageclasses in the prairie vole, Microtus ochrogaster. Growth 32:57-69.

Jameson, E. W., Jr. 1947. Natural history of the prairie vole. Univ. Kansas Publ. Mus. Nat. Hist. 1:125-151.

- 1950. Determining fecundity in male small mammals. J. Mammal. 31:433-436.

Kalela, O. 1957. Regulation of reproductive rate in subartic populations of the vole Clethrionomys rufocanus (Sund.). Suom. Tiedeakat. Toim. (Ser. IV) 34:1-60. 
Keller, B. L. 1968. Reproductive changes in fluctuating populations of Microtus ochrogaster and M. pennsylvanicus in southern Indiana. Ph.D. thesis, Dept. Zoology, Indiana University. $100 \mathrm{p}$.

, and C. J. Krebs. 1970. Microtus population biology III. Reproductive changes in fluctuating population of $M$. ochrogaster and $M$. pennsylvanicus in southern Indiana, 1965-1967. Ecol. Monogr. 40:263-294.

Krebs, C. J. 1964. The lemming cycle at Baker Lake, Northwest Territories during 1959-1962. Tech. Pap. Arct. Inst. N. Am. 15. 104 p.

, M. S. Gaines, B. L. Keller, J. H. Myers, and R. H. Tamarin. 1973. Population cycles in small rodents. Science 179:35-41.

, B. L. Keller, and R. H. Tamarin. 1969. Microtus population biology: demographic changes in fluctuating populations of $M$, ochrogaster and $M$. pennsylvanicus in southern Indiana. Ecology 50:587-607.

, and J. H. Meyers. 1974. Populations cycles in smal! mammals. Adv. Ecol. Res. 8:267-399.

Leslie, P. H., J. S. Perry, and J. S. Watson. 1945. The determination of the median body-weight at which female rats reach maturity. Proc. Zool. Soc. London 115:473-488.

_. U. U. Venables, and L. S. V. Venables. 1952. The fertility and population structure of the brown rat (Rattus norvegicus) in corn-ricks and some other habitats. Proc. Zool. Soc. London 122:187-238.

Lewontin, R. C. 1965. Selection for colonizing ability, p. 77-94. In H. G. Baker and G. L. Stebbins [eds.], The genetics of colonizing species. Academic Press, New York.

Lidicker, W. Z. 1973. Regulation of numbers in an island population of the California vole, a problem in community dynamics. Ecol. Monogr. 43:271-302.

Martin, E. P. 1956. A population study of the prairie vole (Microtus ochrogaster) in northeastern Kansas. Univ. Kansas Mus. Nat. Hist. Publ. 8:361-416.

Mayr, E. 1963. Animal species and evolution. Belknap Press, Cambridge, Massachusetts. 797 p.

Menhusen, B. R. 1963. An investigation of the food habits of four species of rodents in captivity. Trans. Kansas Acad. Sci. 66: 107-112
Myers, J. H., and C. J. Krebs. 1971. Sex ratios in open and enclosed vole populations: demographic implications. Am. Nat. 105:325-344.

Negus, N. C., and A. J. Pinter. 1966. Reproductive responses of Microrus montanus to plants and plant extracts in the diet. J. Mammal. 47:596-601.

Pelikan, J. 1970. Embryonic resorption in Microtus arvalis (Pall.). Zool. Listy 19:93-102.

Pinter, A. J., and N. C. Negus. 1965. Effects of nutrition and photo-period on reproductive physiology of Microtus montanus. Am. J. Physiol. 208:633-638.

Richmond, M. E. 1967. Reproduction of the vole, Microtus ochrogaster. Ph.D. thesis, Dept. Zoology, Univ. Missouri, Columbia, Missouri. 100 p.

, and C. H. Conaway. 1969. Induced ovulation and oestrous in Microtus ochrogaster. J. Reprod. Fertil. Suppl. 6:357-376.

Rose, R. K. 1974. Reproductive, genetic and behavioral changes in populations of the prairie vole, Microtus ochrogaster, in eastern Kansas. Ph.D. thesis, Dept. Systematics and Biology, Univ. Kansas, Lawrence, Kansas. 129 p.

Sadleir, R. M. F. S. 1965 . The relationship between agonistic behavior and population changes in the deermouse, Peromyscus maniculatus (Wagner). J. Anim. Ecol. 34:331352.

1969. The ecology of reproduction in wild and domestic mammals. Methuen and Co., Ltd. 321 p.

Schaffer, W. M., and R. H. Tamarin. 1973. Changing reproductive rates and population cycles in lemmings and voles. Evolution 27:111-124.

Siegel, S. 1956. Nonparametric statistics for the behavioral sciences. McGraw-Hill Book Co. 312 p.

Snyder, D. P. 1969. Corpora bodies in the ovaries of meadow voles (Microtus pennsylvanicus) by serial sectioning versus gross examination. Am. Midl. Nat. 81:592-594.

Stein, G. H. W. 1957. Materialien zur Kenntnis der Feldmaus, Microtus arvalis. P. Z. Sacugetierkd. 22:117-135. (From Keller and Krebs [1970]—original not seen.) 